\title{
A multi-method luminescence dating of the Palaeolithic sequence of La Ferrassie based on new excavations adjacent to the La Ferrassie 1 and 2 skeletons
}

Guerin, Guillaume; Frouin, Marine; Talamo, Sahra; Aldeias, Vera; Bruxelles, Laurent; Chiotti, Laurent; Dibble, Harold L.; Goldberg, Paul; Hublin, Jean-Jacques; Jain, Mayank

Total number of authors:

20

Published in:

Journal of Archaeological Science

Link to article, DOI:

10.1016/j.jas.2015.01.019

Publication date:

2015

Document Version

Peer reviewed version

Link back to DTU Orbit

Citation (APA):

Guerin, G., Frouin, M., Talamo, S., Aldeias, V., Bruxelles, L., Chiotti, L., Dibble, H. L., Goldberg, P., Hublin, J-J., Jain, M., Lahaye, C., Madelaine, S., Maureille, B., McPherron, S. J.'P., Mercier, N., Murray, A. S., Sandgathe, D., Steele, T. E., Thomsen, K. J., \& Turq, A. (2015). A multi-method luminescence dating of the Palaeolithic sequence of La Ferrassie based on new excavations adjacent to the La Ferrassie 1 and 2 skeletons. Journal of Archaeological Science, 58, 147-166. https://doi.org/10.1016/j.jas.2015.01.019

\section{General rights}

Copyright and moral rights for the publications made accessible in the public portal are retained by the authors and/or other copyright owners and it is a condition of accessing publications that users recognise and abide by the legal requirements associated with these rights.

- Users may download and print one copy of any publication from the public portal for the purpose of private study or research.

- You may not further distribute the material or use it for any profit-making activity or commercial gain

- You may freely distribute the URL identifying the publication in the public portal 
1 A Multi-method Luminescence Dating of the Palaeolithic Sequence of La Ferrassie Based on New

2 Excavations Adjacent to the La Ferrassie 1 and 2 Skeletons

3 Guillaume Guérin ${ }^{1,2}$, Marine Frouin ${ }^{2}$, Sahra Talamo ${ }^{3}$, Vera Aldeias ${ }^{3}$, Laurent Bruxelles ${ }^{4,5,6}$, Laurent

4 Chiotti $^{7}$, Harold L. Dibble ${ }^{8,9,3}$, Paul Goldberg ${ }^{10,11}$, Jean-Jacques Hublin ${ }^{3}$, Mayank Jain ${ }^{1}$, Christelle Lahaye ${ }^{2}$,

5 Stéphane Madelaine ${ }^{12}$, Bruno Maureille ${ }^{13}$, Shannon J.P. McPherron ${ }^{3}$, Norbert Mercier ${ }^{2}$, Andrew S.

6 Murray $^{14}$, Dennis Sandgathe ${ }^{15}$, Teresa E. Steele ${ }^{16,3}$, Kristina J. Thomsen $^{1}$, Alain Turq ${ }^{12,13}$.

$7{ }^{1}$ Center for Nuclear Technologies, Technical University of Denmark, DTU Risø Campus, DK-4000 Roskilde,

8 Denmark.

92 Institut de Recherche sur les Archéomatériaux, UMR 5060 CNRS - Université Bordeaux Montaigne, 10 Centre de Recherche en Physique Appliquée à l'Archéologie (CRP2A), Maison de l'archéologie, 33607

11 Pessac cedex.

$12{ }^{3}$ Department of Human Evolution, Max Planck Institute for Evolutionary Anthropology, Leipzig, Germany.

$13{ }^{4}$ Institut National de Recherches Archéologiques Préventives, 7 rue de Madrid, 75008 Paris, France

$14{ }^{5}$ Laboratoire TRACES, UMR 5608 CNRS-Université de Toulouse (Le Mirail), Maison de la Recherche, 1531058 Toulouse Cedex 9, France

$16{ }^{6}$ School of Geography Archaeology and Environmental Studies, University of the Witwatersrand, Private 17 Bag 3, Wits 2050, Johannesburg, South Africa

18 'Département de Préhistoire, Muséum national d'histoire naturelle, UMR 7194 du CNRS, abri Pataud, 1924620 Les Eyzies-de-Tayac, France.

$20{ }^{8}$ Department of Anthropology, University of Pennsylvania, Philadelphia, USA.

$21{ }^{9}$ Institute for Human Origins, Arizona State University, USA.

$22{ }^{10}$ Institute for Archaeological Sciences, University of Tübingen, Rümelinstr. 23, 72070 Tübingen,

23 Germany.

$24{ }^{11}$ Department of Archaeology, Boston University, Boston, USA.

$25{ }^{12}$ Musée national de Préhistoire, F-24620 Les Eyzies-de-Tayac, France.

$26{ }^{13}$ CNRS, Univ. Bordeaux, MCC, PACEA, UMR 5199, F-33400 Talence, France. 
$1{ }^{14}$ Nordic Laboratory for Luminescence Dating, Department of Geoscience, Aarhus University,

2 DTUNutech, Risø Campus, DK-4000 Roskilde, Denmark.

$3{ }^{15}$ Human Evolution Studies Program and Department of Archaeology, Simon Fraser University, Burnaby,

4 Canada.

$5{ }^{16}$ Department of Anthropology, University of California, Davis, Davis, California, USA.

6 Corresponding author: G. Guérin (guillaume.guerin@u-bordeaux-montaigne.fr) 


\section{Abstract}

2 A new interdisciplinary project was initiated to excavate a portion of the Palaeolithic site of La Ferrassie

3 left intact by earlier excavations. One of the aims of this project was to provide chronological

4 information on the succession of Middle and Upper Palaeolithic layers, as well as on the skeletons

5 unearthed by Capitan and Peyrony in the early 1900's. We report here preliminary results on the lithics,

6 faunal remains, site formation processes, and on the stratigraphic context of the La Ferrassie 1 and 2

7 skeletons that were found adjacent to our excavations. Finally, results from luminescence dating of the

8 sediments and a preliminary set of radiocarbon ages are presented. Quartz OSL, both at the multi-grain

9 and single-grain levels of analysis, and post-IR IRSL of feldspar at various stimulation temperatures are

10 compared. The quartz/feldspar comparison revealed a bleaching problem for the quartz OSL (and the

11 feldspar pIRIR signals) from Layer 2; as a consequence, the age of this Layer was determined using a

12 minimum age model.

13 A Mousterian industry with bifaces, at the base of the sequence, has been dated between $91 \pm 9$ and 44

$14 \pm 3 \mathrm{ka}$. The Ferrassie Mousterian layers are attributed to MIS 3, between $54 \pm 3$ and $40 \pm 2 \mathrm{ka}$, and thus

15 appear very late in the final Middle Palaeolithic of the region; furthermore, these ages constrain the

16 chronology of the La Ferrassie 1 and 2 skeletons, which have been attributed to one of these Ferrassie

17 Mousterian layers. The Châtelperronian layer is dated to $42 \pm 3 \mathrm{ka}$ and the Aurignacian to $37 \pm 2 \mathrm{ka}$.

18 Implications of the ages for the La Ferrassie 1 and 2 skeletons, and for the variability of late Mousterian,

19 are discussed.

20 Key-words: OSL dating; post-IR IRSL dating; single grain; Middle Palaeolithic; Mousterian. 


\section{Introduction}

2

3

4

For over a century, the Palaeolithic site of La Ferrassie has been the focus of numerous excavations and studies. Located in a small tributary valley of the Vézère River in southwest France (Fig. 1), this site has yielded rich Middle and Upper Palaeolithic lithic assemblages, faunal remains, as well as two nearly complete Neanderthal skeletons and additional partial skeletons. The human remains make La Ferrassie one of the more important sites for the study of Neanderthal morphology and one of the more important data sets when discussing Neanderthal treatment of the dead (Capitan and Peyrony, 1921a, 1922; Peyrony, 1934, 1921; Vandermeersch, 1976; Harrold, 1980; Heim, 1982a, 1982b, 1976, 1968; Chase and Dibble, 1987; Bar Yosef, 1988; Smirnov, 1989; Straus, 1989; Gargett, 1989, 1999; Duday et al., 1990; Lindly and Clark, 1990; Binant, 1991a, 1991b; Defleur, 1993; Riel-Salvatore and Clark, 2001; Pettitt, 2002; Maureille and Vandermeersch, 2007; Langley et al., 2008). The site also gives its name to one variant of the Mousterian rich in scrapers made on Levallois flakes, and the Aurignacian portion of the sequence was originally used to define its stages (Peyrony, 1934; Bordes, 1957, 1961; SonnevilleBordes, 1960; Delporte, 1984).

Thus there are many reasons why La Ferrassie has been studied in detail. However, aside from some radiocarbon ages completed on Upper Palaeolithic layers from excavations led by Delporte in the 1970s, this key site has remained undated. To address this lack of chronology, we undertook a new interdisciplinary excavation (led by AT) that started in 2010. The first season resulted in the discovery of new deposits in the western portion of the site, very close to the find location of the La Ferrassie 2 skeleton; a great part of the La Ferrassie sequence is represented in these new deposits. Since then, new excavations have been undertaken (i) to re-evaluate the stratigraphic sequence of this area, with a particular emphasis on site formation processes and their implications for the context of the Neanderthal skeletons, (ii) to re-assess the techno-complexes and in particular the eponymous Ferrassie 
1 Mousterian in the current context of Mousterian occupations in SW France (Turq et al., 2008a), and

2 finally (iii) to determine the chronology of the different occupations.

3 Here we report results derived from the use of various luminescence dating methods and compare them

4 with preliminary radiocarbon ages. The results give a coherent chronology that (i) places the base of the

5 sequence at approximately $90 \mathrm{ka}$, (ii) shows that the Mousterian with bifaces is older than most similar

6 industries in southwest France, (iii) demonstrates that the Ferrassie Mousterian is quite late in the

7 sequence, and (iv) shows that the La Ferrassie 2 skeleton is most likely dated to $43 \pm 3$ ka and cannot be

8 older than $54 \pm 4$ ka, which does not confirm expected older ages (e.g., Turq et al., 2008b).

\section{2. Presentation of the site}

10 The first and most extensive excavations of the so-called Grand Abri or Large Shelter at La Ferrassie

11 were led by Peyrony and Capitan over a century ago (1934; see also Capitan and Peyrony, 1909; 1910;

12 1912; 1921; Breuil, 1921). They excavated a series of trenches starting near the road and progressively

13 working towards the east or deeper into the supposed shelter (see below). They defined an

14 archaeological sequence of Mousterian with bifaces, Ferrassie Mousterian, Châtelperronian (initially

15 Lower Perigordian), Aurignacian and Gravettian (initially Upper Perigordian). This work was followed,

16 from 1968 to 1973, by more limited excavations by Delporte (1984) focused almost exclusively on the

17 eastern, interior part of the site. As a result of this work, the site today can be divided into two parts: an

18 inner part to the east where the large section cleaned by Delporte is now preserved, and an outer part

19 or entrance in the northwest sandwiched between the modern road and rock wall that forms an

20 enclosure around the inner part (Fig. 2). Prior to the new excavations, it was uncertain whether any

21 intact deposits remained in this portion of the site, but the general assumption was that it had been

22 entirely excavated by Peyrony and Capitan and subsequently back filled (Laville, 2007). 
1 In 2010 we opened this part of the site (Fig. 2) and encountered extensive, previously unexcavated,

2 deposits corresponding to the base of La Ferrassie sequence, as previously defined. This area (our Sector

3 I) extends to the underlying bedrock. In the northern portion of the new excavation, we also

4 encountered what appears to be the upper part of the classic sequence. This became Sector II because

5 the stratigraphic link with the base of the sequence was not clear at the time. In 2011 we were able to

6 confirm the presence of a complete sequence in Sector II and began work to link Sectors I and II across

7 the western part of the excavated area where substantial intact deposits remained. This western area

8 became Sector III. In 2012 we expanded work in all three sectors, and as a result we were able to link

9 the separate stratigraphic sequences into a single, unified sequence that is the basis of what is reported

10 here. However, there is still some lateral variation in the upper layers, particularly in Layer 7, which

11 remains to be fully described. Thus for Layer 7 we retain a western and eastern separation (former

12 Sector III and II, respectively).

\subsection{Geology of the site}

The shelter is part of an extensive tunnel-like karstic system at the intersection of two roughly perpendicular valleys (Fig. S1). Table 1 provides a simplified description of the geology and lithics of the stratigraphic units based on the new excavation (Fig. 3). Correspondences with Peyrony's original

17 stratigraphy and $\mathrm{OSL} /$ radiocarbon sample provenance are also indicated in Table 1 . In general, the 18 sediments are fluvially-deposited sands and gravels overlain by slope deposits; Turq et al. (2012; see chapter by Goldberg et al.) studied the nature of these deposits in the current part of the excavation.

The transition from fluvial to slope deposits occurs between Layers 2 and 3. Fig. S2 shows the average

21 grain size distribution for the OSL samples from La Ferrassie determined by laser diffraction grain-size

22 analysis, after the $>1 \mathrm{~mm}$ fraction has been removed. Sand and silt contribute respectively about 75 and

$2325 \%$ of the total, and only minor variations are present from layer to layer. 


\subsection{Lithics}

Assemblage sizes from the new excavations are still small but sufficient to generally confirm the presence of the sequence as defined by Peyrony and Capitan and refined by Delporte. A Middle Palaeolithic industry is present at the base of the sequence, in Layers 1 and 2 ( $N=682$ artefacts $>2.5 \mathrm{~cm}$ ), with discoidal and Levallois technology. A partial biface comes from Layer 1 and a complete biface from Layer 2. The biface, in terms of size and shape, fits within the variability defined for the Mousterian of Acheulian Tradition (MTA). However, aside from bifacial manufacture flakes, no other specifically MTA elements are present. Among retouched tools are scrapers, one pseudo-Levallois point, notches, and denticulates. Overall the assemblages are similar to the Mousterian with bifaces described by Peyrony (1934). The Layer 3 assemblage $(\mathrm{N}=434)$ has relatively few Levallois flakes, more notched tools than scrapers, one biface, and some evidence for small flake production in the form of truncated-facetted pieces. Layers 4 and $5(\mathrm{~N}=620)$ are consistent with a Ferrassie type Mousterian, based on a Levallois technology with a predominance of single, double, and convergent scrapers along with truncatedfacetted pieces, notches, and denticulates. The Layer 6 assemblage is still quite small ( $\mathrm{N}=164$ plus 91 pieces from the 1.5-25 mm fraction); nevertheless, it has yielded artefacts typical of the Châtelperronian (see Chiotti in Turq et al., 2012). The assemblage includes nine retouched bladelets including three truncated bladelets and one Dufour bladelet (sub-type Roc-de-Combe). There are also two Châtelperronian point fragments and one other blade fragment with abrupt retouch that could also be a point fragment. The assemblage also includes one end-scraper and three burins. Layer 7 ( $\mathrm{N}=908$ plus 376 pieces from the $1.5-25 \mathrm{~mm}$ fraction) is characterized by an Aurignacian lithic production including bladelets produced from carinated scrapers and at least one Dufour bladelet, of the sub-type Roc-deCombe. Thus far, however, the assemblage does not allow us to determine with certainty which type of Aurignacian is present. 


\subsection{Faunal remains}

The faunal diversity of the current sample is in agreement with what has been previously reported for the sequence (Peyrony, 1930) and further supports the stratigraphic correlation proposed in Table 6. In the older part of the sequence (Layers 1 through 5b), large bovids (aurochs [Bos primigenius] and/or bison [Bison priscus]) dominate the assemblages, and when these elements can be identified more specifically, they are from bison. Red deer (Cervus elaphus) and roe deer (Capreolus capreolus) are also common in these older assemblages. A few elements of reindeer (Rangifer tarandus) and horse (Equus simplicidens) are also found. Specifically, Layer 3 has also yielded remains of woolly mammoth (Mammuthus primigenius) and woolly rhinoceros (Coelodonta antiquitatis). In Layer 4, the presence of wild boar (Sus scrofa) together with red deer and bovids may indicate more temperate conditions, but reindeer are present there, too. Many of the assemblages contain species characteristic

12 of a diversity of habitats: reindeer are usually considered part of a colder, drier, more open environment 13 whereas roe deer are considered part of a warmer, more wooded environment. The topographic relief of the region may have created microhabitats that allowed the persistence of a diversity of species.

15 Time averaging over minor climatic fluctuations may also contribute to the variability. Reindeer clearly dominate the upper part of the sequence (Layers 6 and 7); they are almost exclusive in the large sample

17 from layer 7. Zooarchaeological analyses have demonstrated an abundance of cutmarks, burned bones, and breakage of fresh bones for marrow exploitation throughout the La Ferrassie sequence; bone surfaces are generally well-preserved allowing for sufficient reading of the modifications. Carnivore

20 remains, coprolites, and traces of carnivore activity such as chewed and digested bones are rare. Human

21 activity was the main agent for the accumulation of faunal remains throughout the deposits.

\subsection{Micromorphology and the stratigraphic position of the La Ferrassie 2 foot}


An analysis of historical photographs of the Peyrony and Capitan excavations and of the various published and unpublished maps (Laville, 2007) in combination with our own excavations in the same area allow us to place the La Ferrassie 2 skeleton to within $\sim 1-2 \mathrm{~m}$ of the stratigraphic section sampled here (Fig. 4c). The observations made by the original excavators and by the members of the scientific commission prior to removal of the skeleton attributed the skeleton to the base of Layer C (our Layer 4) and noted that it was covered by Layer D (our Layer 5 ). In terms of the spatial association between La Ferrassie 1 and 2, Peyrony clearly thought they were stratigraphically very close. La Ferrassie 1 is described as lying almost on the yellowish layer and sometimes on the reddish layer underneath ("... reposant presque sur la couche jaunâtre et parfois rougeâtre sous-jacente ...") (Peyrony 1934: 24). He describes La Ferrassie 2 as occurring at about the same level and only $50 \mathrm{~cm}$ from La Ferrassie 1 ("...

11 sensiblement au même niveau et dans le même axe que le premier squelette, mais en position inverse, 12 puisque les deux têtes n'étaient qu'a 0 m. 50 l'une de l'autre ...") (Peyrony, 1934: 26). In an attempt to establish/constrain the stratigraphic position of La Ferrassie 2 in the newly excavated sequence, we (AT, PG, and SM) examined the foot of the skeleton stored in the Musée de

15 I'Homme, Paris. A large block of sediment is still attached to the base of the right foot of this specimen, 16 and it was examined along with a complete suite of thin sections collected from of our excavations. The 17 purpose of the investigation was to (i) examine the sediments adhering to the foot to compare them with those from our excavations, and thereby (ii) determine the stratigraphic layer from which it was excavated.

The sediments attached to the foot consist of consolidated (by the Musée) yellow brown silty 21 sands with burned and unburned bone and some lithics scattered throughout (Fig. 4a). When these 22 sediments are compared to those exposed in our sequence (Fig. 4b), we observe a remarkably close 23 correspondence to those of Layer 5; the same components and abundances are observed. Whereas 
1 Layers 4 and 5 are generally similar, the latter is noticeably richer in bone (Fig. 4b), which makes it a

2 closer match to the sediments attached to the hominin specimen. At the same time, we can say that

3 Layer 6 contrasts greatly with Layers 4 and 5 both in terms of the sediments and their cultural content.

4 The sediments preserved under the foot do not match Layer 6 nor do they look like a mix of Layers 5 and

56 as might happen if a burial pit was excavated from 6 into 5 and then refilled. Thus association with

6 Layer 6 can be excluded, and it remains to be determined whether Layer 4 or 5 is the better candidate

7 for the sediment under the skeleton.

The question as to whether the skeletons represent burials, and the definition of the latter, are

9 beyond the scope of this study. Our ongoing study of the processes leading to the formation of the site

10 and the documentation of the original discoveries is expected to shed more light on this question.

\section{Material and methods}

\subsection{Sampling}

13 Given the importance of the site, we decided on a multi-method dating programme. In the almost 14 complete absence of heated stones, only sediments were sampled for luminescence dating, but these 15 covered the entire stratigraphic sequence. Some samples were measured in two different laboratories 16 to provide inter-laboratory comparisons. Since an overlap with the range of radiocarbon dating was 17 considered possible, bone samples were also selected for radiocarbon dating from the top of the Mousterian (Layer 5b) and from Layer 6 (Châtelperronian) in Sector II to provide additional age control.

The two main series of sediment samples were collected from Sectors I and II (Figs. 2, 3; Table 1)

21 lighting. After cleaning the sections, $\sim 1 \mathrm{~cm}$ of exposed sediment was removed before actual sampling. At

22 that stage, Sector III was not yet excavated, so the two sampled sections were not linked in stratigraphy. 
1 In the northwest area (Sector II), the Aurignacian, Châtelperronian, and Ferrassie Mousterian Layers

2 were sampled (Layers 4-7 - see Table 1 for the relationship between luminescence samples and

3 archaeological layers). One sample was taken per layer, except for the Mousterian layers; bearing in

4 mind the presence of Neanderthal skeletons in this part of the sequence and the closeness of the La

5 Ferrassie 2 skeleton ( 1-2 $\mathrm{m}$ east of the sampling location), paired samples were taken from these

6 layers. In this area, only a thin wall of sediments remained from the Peyrony and Capitan excavations.

7 Because of this, the sediment samples were taken close to the bedrock wall (less than $20 \mathrm{~cm}$, possibly 10

$8 \mathrm{~cm}$ ); this led to additional complexity in the assessment of the gamma dose-rates (see section 4.2 -

9 dose-rates). A further six samples were taken from the trench in Sector I, two from each Mousterian

10 Layer (1, 2 and 3).

The excavations in Sector III in 2012 provided a stratigraphic link between Sectors I and II, and

12 led to the current unified stratigraphy (Fig. 3). It was, therefore, decided to sample Layer 5 in this sector.

13 Finally, another sample, also taken in 2012, comes from Layer 3 at the south end of Sector I. Both

14 samples were collected during the day under opaque black covering. Fig. S3 shows an interactive 3D

15 model of the excavated portion of the site, indicating approximate sampling location (only approximate

16 since the 3D model corresponds to the state of the site two years after the first sampling campaign).

Luminescence dating methods are applicable to different minerals (e.g., quartz and feldspar) measured using different signals and displaying different characteristics in terms of dose-rates, equivalent doses, signal resetting rates when exposed to daylight (hereafter called bleaching rates), etc.

They can thus be regarded as complementary tools when combined to study one site (e.g., Richter et al.,

21 2009; Guérin et al., 2012a). For the study of La Ferrassie, we decided to compare ages obtained from

22 both quartz and feldspar. As the bleaching rates of the luminescence signals of these two minerals are

23 very different (by orders of magnitude), the apparent ages can be used to assess the likelihood of age 
overestimation resulting from incomplete bleaching at the time of burial (Murray et al., 2012). This is particularly important for slope deposits filling a rockshelter.

\subsection{Luminescence}

\subsubsection{Sample preparation and instrumentation}

\section{Chemical preparation}

The sediment samples were first split into different portions for grain size analysis, highresolution gamma spectrometry and mineral separation (performed entirely under controlled low-level yellow light suitable for luminescence samples). Prior to mineral separation the samples were wet sieved to isolate the $180-250 \mu \mathrm{m}$ sand fractions. This sieving step was undertaken before any chemical treatment and in particular before treatment with hydrochloric acid $(\mathrm{HCl})$, so that any $\mathrm{mm}$ to $\mathrm{cm}$ scale calcareous aggregates and/or gravels were less likely to release quartz grains of the size range of interest. After sieving, the samples were treated with $\mathrm{HCl}(10 \%)$ to remove carbonates, and then with hydrogen peroxide $\left(\mathrm{H}_{2} \mathrm{O}_{2}\right)$ to remove organic contaminants; both treatments were continued until no reaction was visible. The sieved and disaggregated grains were subsequently treated with dilute hydrofluoric acid $(\mathrm{HF}, 10 \%)$ for 30 minutes to clean all grain surfaces and to etch the outer rim of feldspar, and finally rinsed with $10 \% \mathrm{HCl}$. Two aqueous solutions of sodium heteropolytungstates (densities 2.58 and $2.62 \mathrm{g.cm}{ }^{-3}$ ) were used to isolate K-rich feldspar fractions $\left(<2.58 \mathrm{~g} . \mathrm{cm}^{-3}\right)$ and quartz $\left(>2.62 \mathrm{~g} . \mathrm{cm}^{-3}\right)$. The quartz fraction was then etched with HF (40\%) for 40 minutes to remove the outer portion of the grains affected by alpha irradiation. After etching, any fluoride contaminants were removed by rinsing with $10 \% \mathrm{HCl}$. This fraction was then re-sieved at $180 \mu \mathrm{m}$ for further analysis and in particular for single grain measurements; this latter step removes any small grains resulting for example, from the dissolution of residual feldspar in the quartz-rich fraction. 
Grains were mounted in $9 \mathrm{~mm}$ base diameter stainless steel cups using silicone oil. Aliquots of

$3 \sim 3 \mathrm{~mm}$ in diameter, comprising several hundreds of grains, were measured for both quartz and feldspar

4

extracts. Luminescence measurements were made using Ris $\varnothing$ TL/OSL DA-15 and DA-20 readers; for quartz, blue $(470 \mathrm{~nm})$ light-emitting diodes (LED) were used with $7.5 \mathrm{~mm}$ Hoya U-340 detection filters; for feldspar, IR diodes emitting at $875 \mathrm{~nm}$ were used in combination with coupled Schott BG39 and Corning 7-59 detection filters (transmission 320-460 nm; Bøtter-Jensen et al., 2003; 2010). Each ${ }^{90} \mathrm{Sr} /{ }^{90} \mathrm{Y}$ source was calibrated during the measurement period by measuring several aliquots of calibration quartz dosed with gamma rays (4.81 Gy) from a national secondary-standard ${ }^{137} \mathrm{Cs}$ source; this calibration has been independently confirmed by Bos et al., 2006.

Single grains of quartz were measured using an automated Risø TL/OSL reader (DA 20) fitted with a single grain attachment (Duller et al., 1999; Bøtter-Jensen et al., 2000). The grains were loaded into aluminium single-grain discs; each disc contains 100 holes $300 \mu \mathrm{m}$ in diameter and $300 \mu \mathrm{m}$ deep, drilled on a 10x10 rectangular grid with $600 \mu \mathrm{m}$ spacing between centres. A green laser (532 nm) was used with a $7.5 \mathrm{~mm}$ Hoya U-340 detection filter. To confirm that only one grain was loaded into each hole, the single grain discs were visually inspected using a microscope before measurement. The spatial homogeneity of the ${ }^{90} \mathrm{Sr} /{ }^{90} \mathrm{Y}$ beta source (ID 155, produced prior to 2000) used for the single grain measurements presented here was determined using radiochromic film (GAFCHROMIC EBT2) and the coefficient of variation was found to be $\sim 5 \%$, which is unlikely to affect our dose distributions significantly. Using the approach developed by Lapp et al. (2012) to correct for spatial beta source heterogeneity, no significant changes in dose or scatter in our dose distributions could be detected, consistent with the observations of Sim et al. (2014) for the same source. Thus, the dose rate employed in further single grain calculations is based on the average over the whole disc. 
Given the importance of the site, it was decided to conduct separate, blind comparisons of equivalent dose measurements on quartz aliquots between two laboratories: the Centre for Research in Physics Applied to Archaeology (CRPAA) in Bordeaux (France) and the Centre for Nuclear Technologies, Danish Technical University (DTU Nutech), Ris $\varnothing$ Campus (hereafter Ris $\varnothing$ ). Where available, the numbers obtained by both laboratories will be provided.

\subsubsection{Dose-rates}

Quartz and feldspar grains accumulate dose in sediments because of the exposure to external alpha, beta, gamma and cosmic rays and particles; there are also internal contributions - especially in

10 the case of K-rich feldspar. The internal dose-rate was assumed to be $0.06 \pm 0.03 \mathrm{~Gy} \cdot \mathrm{ka}^{-1}$ for quartz

11 (Mejdahl, personal communication to Murray, based on Mejdahl, 1987), and was calculated for feldspar

12 using dose-rate conversion factors for potassium (Guérin et al., 2011) and assuming a potassium content

13 equal to $12.5 \pm 0.5 \%$ (Huntley and Baril, 1997). The self-dose fraction of the infinite-matrix dose-rate was

14 taken from Guérin et al. (2012b). The contribution from Rb was calculated according to Readhead (2002)

15 and Huntley and Hancock (2001). Direct potassium measurements of K-rich extracts using a recently-

16 developed XRF system attached to a Ris $\varnothing$ luminescence reader confirmed the expected high potassium

17 content. Finally, it was assumed that the HF etching had removed the alpha irradiated portions of the

18 quartz and feldspar grains; therefore, no external alpha dose-rate was taken into consideration. Cosmic

19 dose-rates were estimated from the estimated burial depth of the sediments according to Prescott and Hutton (1988) and contributed $\sim 10 \%$ of the total dose-rates. 
Sediment was homogenised by crushing and sealed in plastic boxes containing $\sim 10 \mathrm{~g}$ of samples.

2 These sealed samples were then stored for at least three weeks to ensure radon build-up, before

3

4 measurement using high resolution, low background gamma spectrometry. For each sediment sample, the potassium, uranium and thorium contents were measured; the state of equilibrium of the U-series has been evaluated. For that purpose, two effective $U$ contents were calculated using weighted averages obtained from different gamma lines: the first, based on the top members of the chain, included the rays at $63 \mathrm{keV}$ and $93 \mathrm{keV}\left({ }^{234} \mathrm{Th}\right), 143 \mathrm{keV}$ and $186 \mathrm{keV}\left({ }^{235} \mathrm{U}\right)$ and $1001 \mathrm{keV}\left({ }^{234 \mathrm{~m}} \mathrm{~Pa}\right)$. The second value was calculated from the lines at $295 \mathrm{keV}$ and $352 \mathrm{keV}\left({ }^{214} \mathrm{~Pb}\right)$, and 609, 1120 and $1764 \mathrm{keV}$ $\left({ }^{214} \mathrm{Bi}\right)$. For samples FER 7-14, both values agree at one sigma. For the remaining (samples FER 1-6), we calculated extreme scenarios: we calculated the dose-rate using either the top or the bottom chain value as representative of the whole U-series. Given the uranium contribution to the total dose-rates ( $20-25 \%)$, the differences between the extreme scenarios resulted in discrepancies of $\sim 5 \%$ on average. Given the final uncertainties on the ages, we decided that a detailed analysis of the source of disequilibrium was not necessary. We thus calculated dose-rate values based on the pre- and postRadon contents in the U decay series, using factors from Guérin et al. (2011).

External beta dose-rates for both quartz and feldspar were calculated from $\mathrm{K}, \mathrm{U}$, and Th contents using the factors from Guérin et al. (2011). Grain size attenuation factors were taken from Guérin et al. (2012b). For the effect of moisture on beta dose-rates, values provided by Nathan and Mauz (2008) were used, although they do not include geometric factors and are therefore likely to be underestimates (Guérin et al., 2012b). However, these moisture correction values only apply to the water content of the sediment (Zimmermann, 1971), which typically amounts to 15\% of the total (see below); errors in the moisture correction term will thus result in errors of less than a few $\%$ in the doserate. The effect of etching on the mean dose-rate was corrected for using values from Nathan (2011). The moisture content of the sediments during burial time must have been different from the values 
measured immediately after sampling, because the stratigraphic sections had been exposed to air for several days before sampling and had dried out significantly. Measurements of saturation content yielded maximum values of $\sim 25 \%$, on average. We took $0.6 \pm 0.2$ as a representative value for the fraction of saturation, leading to a moisture content equal to $15 \pm 5 \%$ of water content (expressed as mass of water/dry mass). The actual lifetime average water content cannot have been greater than saturation (25\%), and it is inconceivable that it could have been (on average) less than $5 \%$ (average at the time of sampling). Thus the two standard deviation range of 5-25\% covers all possible water content scenarios; the average water content between these two extreme scenarios represents our best guess regarding 9 burial time.

Following Guérin et al. (2012b), the use of the infinite matrix assumption (Aitken, 1985) may be questioned, especially in light of the grain size analysis (Fig. S2) which shows that the sediment samples

12 from La Ferrassie are mainly composed of sands, i.e. of grains of non-negligible dimensions compared to 13 the range of electrons - whether of primary electrons from beta decay or of secondary from 14 photoelectric/Compton interactions of primary photons. The two main dosimetric effects identified by Guérin et al. (2012b) are: (i) the inappropriate use of beta dose-rate attenuation factors (first defined by Mejdahl, 1979) since there is no homogeneous, infinite matrix containing the radioelements and 17 surrounding the dated quartz/feldspar grains; (ii) the unaccounted self-dose to potassium feldspar, which are point like sources of non-negligible size compared to the range of beta particles. It has been shown by Guérin et al. (2012b), using numerical simulations, that for well-sorted sands in which potassium feldspar and quartz grains have the same grain-size distribution, these two effects compensate because the self-dose fraction $\phi$ is the same factor as the one used in beta attenuation

22 calculations (1- $\phi)$. A detailed study of these effects for the sediments from La Ferrassie is beyond the 23 scope of this study; however, a few comments are appropriate. Firstly, the presence of potassium 24 feldspar in the sand fraction and in particular in the $180-250 \mu \mathrm{m}$ fraction used for $D_{e}$ measurements 
1 indicates that there is at least some self-dose to K-feldspar to compensate for the inappropriate beta

2 attenuation correction. Secondly, the observed bimodal grain size distributions (cf. Fig. S2) complicate

3 the problem, since it is not unlikely that the radioelement contents are different in the two modes - in

4 particular it is well-known that clay fractions are usually more radioactive than sands. Since radionuclide

5 concentrations in these sediment samples are thus likely to be grain size dependent, the two dosimetric

6 effects might not strictly compensate each other. If indeed the silt fraction contained more radioactivity,

7 then there should be no self-dose, and, on average, no attenuation effect (cf. Fig. 3, in Guérin et al.,

8 2012) so our calculated dose-rates would underestimate the true external beta dose-rates received by

9 quartz and feldspar grains. The presence of sand size K-feldspar indicates only that this phenomenon does not fully affect - if it does at all - our samples, so we have adopted a conservative approach and

11 calculated beta dose-rates using the infinite matrix approximation.

\section{Gamma dose-rates}

Gamma dose-rates were measured in situ by burying $\mathrm{Al}_{2} \mathrm{O}_{3}: \mathrm{C}$ crystal chips ( $1 \mathrm{~mm}$ thickness, 5

$14 \mathrm{~mm}$ in diameter) in the sections in aluminium tubes (length: $30 \mathrm{~cm}$, diameter: $1 \mathrm{~cm}$ ). The dosimeters

15 were left in place for one year and measured using a Daybreak 2200 OSL reader system (Bortolot, 2000) combining green light stimulation (Nichia NSPG310) with $7.5 \mathrm{~mm}$ Hoya U-340 filters, using the same

17 protocol as Richter et al. (2010). These measurements are generally representative of present-day 18 gamma dose-rates, because they characterize a volume of $\sim 1 \mathrm{~m}^{3}$ (Guérin and Mercier, 2011) surrounding the measurement point. In contrast, samples analysed in high resolution spectrometry use $\sim 10 \mathrm{~g}$ of material; using the resulting $\mathrm{K}, \mathrm{U}$, and Th concentrations to derive gamma dose-rates assumes

21 that these $10 \mathrm{~g}$ are representative of the $\sim 1000 \mathrm{~kg}$ of sediment contributing to the gamma dose-rate. In

22 'lumpy' (Brennan et al., 1997) environments such as a karstic rockshelter, where one avoids taking 23 calcareous lumps in the samples, the situation is clearly problematic since these low radioactivity 
minerals will not be measured in gamma spectrometry but will contribute to gamma dose-rates. On the

2 other hand, in situ dosimeters do not give any information concerning possible radionuclide disequilibrium, and so cannot indicate whether dose-rates have been constant through time.

Based on these considerations, we distinguish two different situations for the samples from La

Ferrassie : samples FER 1-6 were taken from sector II, in the section left by the original excavators, and thus came from a thin layer of sediment covering the bedrock wall; on the other hand, samples FER7-14 were taken from horizons whose lateral extent was greater than the typical range of gamma rays in sediments. As a consequence, the systematic differences between gamma dose-rates measured in situ with $\mathrm{Al}_{2} \mathrm{O}_{3}: \mathrm{C}$ dosimeters and those calculated from $\mathrm{K}, \mathrm{U}$, and Th concentrations (Fig. 5; the factors used to correct gamma dose-rates for the effect of humidity were taken from Guérin and Mercier (2012), taking the average value -1.15 - for cubic-centred assemblages with an average grain diameter of $\sim 200$ $\mu \mathrm{m}$ [cf. Fig. S2]) can be explained in two different ways: (i) For samples FER 1-6, the gamma dose-rates measured by dosimeters underestimate the gamma dose-rates received by the samples (by 35-40\%), because the dosimeters were closer to the bedrock wall than the samples. On the other hand, since the $\mathrm{K}, \mathrm{U}, \mathrm{Th}$ values did not include any contribution from the bedrock, these values overestimated the true gamma dose-rates received by the samples. As a consequence, the gamma dose-rates to the samples were taken as the averages between calculated values and those measured in situ, and the error was chosen to cover, at two standard deviations, the interval between these two extreme values. (ii) In the case of samples FER 7-14, where the discrepancies (of $\sim 20 \%$, on average) arose because of the absence of calcareous lumps in samples analysed by high resolution gamma spectrometry, in situ measurements are considered reliable estimates of gamma dose-rates received by the samples during burial. In addition to these systematic differences, there will also be differences arising from the different locations of the dosimeters and gamma spectrometry samples, but dose-rate discrepancies arising from this origin are assumed to induce random rather than systematic differences. Finally, the present-day 
moisture content of $5 \%$ is presumed to represent the average water content throughout the burial time of the dosimeters, and gamma dose-rates measured with dosimeters were corrected for this moisture content before application of the correction during sample burial time ( $\mathrm{WF}=15 \pm 5 \%, c f$. previous subsection). The association between the dosimeters and the samples, and the gamma dose-rate calculations are shown in Table S2.

\subsection{Radiocarbon}

Bone samples were pre-treated at the Department of Human Evolution, Max Planck Institute for Evolutionary Anthropology (MPI-EVA), Leipzig, Germany, using the method described in Talamo and Richards (2011). The outer surfaces of the bone samples were first cleaned by a shot blaster, and then $500 \mathrm{mg}$ of bone powder was taken. The samples were then decalcified in $0.5 \mathrm{M} \mathrm{HCl}$ at room temperature until no $\mathrm{CO}_{2}$ effervescence was observed, usually for about 4 hours. $0.1 \mathrm{M} \mathrm{NaOH}$ was added for 30 minutes to remove humics. The $\mathrm{NaOH}$ step was followed by a final $0.5 \mathrm{M} \mathrm{HCl}$ step for 15 minutes. The resulting solid was gelatinized following Longin (1971) at $\mathrm{pH} 3$ in a heater block at $75^{\circ} \mathrm{C}$ for $20 \mathrm{~h}$. The gelatine was then filtered in an Eeze-Filter ${ }^{\mathrm{TM}}$ (Elkay Laboratory Products (UK) Ltd.) to remove small $(<8$ $\mu \mathrm{m}$ ) particles. The gelatine was then ultra-filtered with Sartorius "Vivaspin 15" 30 KDa ultrafilters (Brown et al., 1988). Prior to use the filter was cleaned to remove carbon-containing humectants (Higham et al., 2006). The samples were finally lyophilized for 48 hours.

\section{Results}

\subsection{OSL - Multi-grain quartz ( $3 \mathrm{~mm}$ aliquots)}

\section{Signal characteristics and measurement protocol}

The OSL signal from the La Ferrassie quartz is dominated by the fast component (see comparison with the signal from heated calibration quartz in Fig. S4a). The net signal intensity used in 
1 further calculations was derived from the sum of the OSL in the first $0.8 \mathrm{~s}$ of stimulation minus a

2 background signal. An early background subtraction method (Cunningham and Wallinga, 2010) was used

3 to remove any contribution from the medium component of the OSL signal; the background intensity

4 was taken as the sum of the OSL from the interval 0.8 to $3.2 \mathrm{~s}$ of stimulation, and then time averaged. It

5 should be noted here that for sample FER 1, a late background subtraction was also tested (using the

6 last $8 \mathrm{~s}$ of stimulation). With the early background subtraction, the average equivalent dose for this

7 sample is $70.7 \pm 2.0 \mathrm{~Gy}$. With a late background subtraction, this average equivalent dose becomes 70.5

$8+$ - 1.9 Gy. This indicates that for quartz samples from La Ferrassie, whose OSL signal is dominated by

9 the fast component, early and late background subtraction lead to indistinguishable results. SAR sensitivity-corrected dose response curves (Murray and Wintle, 2000; 2003) were constructed (Fig. S4b)

11 using at least four regenerative doses bracketing the natural $D_{e}$. The effect of IR stimulation at $125^{\circ} \mathrm{C}$ of

12 varying duration (from 0 up to 320 s) was tested on sample FER 7 (Fig. S4c) and showed no dependency

13 of $D_{e}$ as a function of IR stimulation duration. Furthermore, the IRSL signal intensity was, on average, less

14 than $1 \%$ than OSL signals. This indicates that the quartz fraction is not contaminated significantly by

15 feldspar and we can thus use a standard SAR protocol without prior IR stimulation. At the end of the SAR

16 cycle, the first regeneration dose was repeated twice to obtain a recycling ratio and an IR depletion ratio

17 (Duller, 2003). Both these ratios were within $\pm 15 \%$ of unity for all aliquots, and no correlation between

18 equivalent dose and IR depletion ratio was observed, confirming that the observed $D_{e}$ was insensitive to

19 IR stimulation, and thus presumably not influenced by signals from feldspar. Recuperation was checked

using a zero dose cycle after measurement of the largest regeneration dose and showed no significant

21 inter-cycle signal transfer. All aliquots (between 16 and 32, depending on the variability in $D_{e}$

22 measurements to obtain comparable relative uncertainties) were thus used in the calculations of the

23 unweighted average equivalent doses (see also discussion in section 4.3 about single grain data

24 analysis). The SAR protocol was applied with various preheat conditions and Fig. S4d shows a preheat 
1 plateau obtained for sample FER 7; each point corresponds to an average of 6 aliquots, except for the

2 preheat temperature of $220^{\circ} \mathrm{C}$ ( 2 high dose outliers were removed). The preheat temperature was held

3 for $10 \mathrm{~s}$ prior to $L_{i}$ measurements. The cutheat temperature (applied before reading the $T_{i}$ signal, used to

4 monitor sensitivity changes) was $40^{\circ} \mathrm{C}$ lower than the preheat temperature. A dose recovery test, using a

5 preheat at $240^{\circ} \mathrm{C}$ for $10 \mathrm{~s}$ and a cutheat of $200{ }^{\circ} \mathrm{C}$, was performed on six aliquots from 10 different

6 samples covering the entire sequence; the given dose ( $60 \mathrm{~Gy}$ ) was delivered to the aliquots in the

7 reader after exposure to a solar simulator (Hönle SOL 2) for 3 hours. The average measured/given dose

8 recovery ratio was $0.98 \pm 0.01$. In Bordeaux, dose recovery tests were independently performed on 4

9 different samples (FER1, 3, 7 and 8) with the same parameters; the average measured to given dose

10 ratio was $0.99 \pm 0.01$. Fig. S5 shows a frequency histogram of dose recovery ratios obtained for

11 individual aliquots ( $n=60)$, indicating that our SAR protocol is able to accurately measure a laboratory

12 dose given before any thermal treatment of the sample (see Table S1, SOM, for the measurement

13 protocol used to estimate equivalent doses). The quartz samples from La Ferrassie thus met all

14 laboratory-based criteria for a reliable estimate of equivalent dose. The uncertainties on individual

15 equivalent doses have been assigned using the Analyst software (Duller, 2007) and include contributions from counting statistics (assuming Poisson statistics) and curve fitting errors.

\section{Data interpretation}

In Table 2 we summarize the relevant dose-rate data and in Table 3 the equivalent doses and resulting multi-grain aliquot quartz ages for all samples. Fig. 6 shows the relationship between archaeological layer and age. Four of the fourteen samples were measured both at Ris $\varnothing$ (Fig. 6, filled

21 black squares) and in Bordeaux (Fig. 6, filled red circles) to ensure that our age estimates are not

22 affected by inter-laboratory systematic errors. These paired ages agree well with each other (three pairs

23 are consistent within one standard error and the fourth is consistent within two standard errors); we 
1 thus consider it unlikely that our ages suffer from significant systematic off-sets that could, for instance,

2 arise from different calibrations of laboratory dose-rates.

There is a general increase of age with burial depth, or more precisely when moving downwards in the stratigraphy (i.e., taking into account the tilting of the layers as evidenced by the fabrics - see chapter by McPherron in Turq et al., 2012). A noticeable exception occurs for sample FER 2 (Layer 6), which appears to be too old; for this sample we have an age inversion that is significant at two standard 7 errors.

Based on observations of sediment thin sections, post-depositional mixing does not appear to have affected the integrity of the different layers. Furthermore, we do not consider it likely that this age inversion is caused by beta dose-rate heterogeneity because neither the mineralogy nor the grain size

11 distributions changed significantly between Layers 5, 6 and 7. On the other hand, a consideration of the 12 process of sediment accumulation through slope transport and deposition mechanisms suggest that 13 incomplete bleaching may be a problem for these samples, i.e. the OSL signal may not always have been 14 adequately reset prior to sediment deposition. At this stage the most likely explanation for the age 15 inversion is incomplete bleaching which at least has affected Layer 6 more than the other layers. This is possibly caused by the fact that Layer 6 as exposed today is quite sandy and non-calcareous. Field

17 evidence shows the presence of decalcified bedrock among the sand, demonstrating that much of the 18 sand is derived from the direct decomposition of the bedrock and was likely little exposed to ambient 19 light before burial.

One approach to investigating the presence of incomplete bleaching is to compare the OSL ages

21 obtained from quartz with IRSL ages obtained from feldspar. Given the different bleaching rates of these

22 two minerals, such a comparison enables us to make qualitative statements about the likelihood of the presence of incomplete bleaching (Murray et al., 2012, and references therein). The quartz OSL signal is 
much more rapidly reset by sunlight than the conventional IRSL signal from feldspar ( 1 order of magnitude difference; e.g. Godfrey-Smith et al., 1988; Thomsen et al., 2008; Buylaert et al., 2012), which means that if the feldspar IRSL ages are comparable to the quartz OSL ages, then both signals are likely to have been sufficiently reset at deposition. If the feldspar ages are significantly greater than the quartz ones, then it indicates that incomplete bleaching may be a problem, at least for feldspar IRSL signals.

\subsection{Feldspar}

Feldspar as a natural luminescence dosimeter has several advantages compared to quartz (e.g., sensitivity and age range) but suffers from an athermal signal instability, known as anomalous fading (Wintle, 1973; Spooner, 1994). The conventional IRSL signal (measured close to room temperature, usually $50^{\circ} \mathrm{C}$, and here identified as $\mid R_{50}$ ) typically fades by $3-5 \%$ per decade of time (Huntley and Lamothe, 2001). However, recent studies have demonstrated the potential of elevated temperature post IR-IRSL protocols (Thomsen et al., 2008; Buylaert et al., 2009), in which a further IR stimulation is made at some elevated temperature after an $\mathbb{I}_{50}$ stimulation, to overcome this problem. In particular, the post-IR IRSL signal at $290^{\circ} \mathrm{C}$ (pIRIR 290 , Thiel et al., 2011) has been shown to be essentially non-fading by experiments on known age samples; this avoids the need for any inherently model-dependent fading corrections (Buylaert et al., 2012). Moreover, Buylaert et al. (2012) have shown that this signal is, in comparison with quartz OSL, very slowly reset by exposure to sunlight - probably orders of magnitude slower than is quartz. As a consequence, $\operatorname{pIRIR}_{290}$ ages can only be greater than, or at best equal to, quartz ages. In the latter case this indicates good bleaching of both signals at the time of deposition. The situation where pIRIR ${ }_{290}$ ages are greater than quartz ages indicates poor bleaching of the pIRIR ${ }_{290}$ signal, but does not necessarily imply poor bleaching of the quartz signal (Murray et al., 2012) - or indeed of the $\mathrm{IR}_{50}$ feldspar signal. 
In this study we have measured K-rich feldspar extracts, not with the intention of providing

2 independently-determined luminescence ages, but as an indicator of the degree of bleaching of quartz.

3 This avoids the need for an accurate estimate of field fading rates and unbleachable residual signals as

4 well as the debate on the applicability of fading correction models to samples $>50$ ka (Huntley and

5 Lamothe, 2001; Morthekai et al., 2008). Murray et al. (2012) have pointed out that because of the

6 differential bleaching rates of quartz and the IRSL and pIRIR signals from feldspar even an incompletely

7 bleached feldspar signal may indicate a well-bleached quartz signal.

Here we have used a SAR based protocol (see Table S1), with 200 s IRSL stimulations. The net signals were calculated using the initial $2 \mathrm{~s}$ of the pIRIR signals after subtracting a background obtained from the last $40 \mathrm{~s}$ of stimulation. We have derived $\mathrm{pIRIR}_{290}$ ages for seven of our samples and the results are given in Table 3 and Fig. 7a. All pIRIR 290 ages are significantly larger than the corresponding quartz

12 ages; indeed the pIRIR 290 signal for FER 12 is so close to saturation that a dose could not be determined

13 ("sat" in Table 3). The average ratio of pIRIR 290 age to multi-grain quartz age is $2.3 \pm 0.3$ ( $n=7$, Fig. 7c, open symbols). Such a large difference in this age range can almost certainly be attributed to incomplete bleaching of at least the pIRIR ${ }_{290}$ signal. Indeed, the measured excess doses for our samples, defined as the post IR-IRSL dose on top of the expected dose based on the quartz age - range from 61 to $490 \mathrm{~Gy}$

17 (Table 3). As a consequence we conclude that for all the measured samples, the pIRIR ${ }_{290}$ signal was probably not completely reset at the time of sediment deposition (although of course this does not necessarily indicate poor bleaching of the quartz signal).

Although the pIRIR 290 signals may not have been completely bleached, the same does not

21 necessarily apply to lower temperature pIRIR signals. Both theoretical models (Jain and Ankjærgaard,

22 2011) and experimental studies (e.g., Thomsen et al., 2008; Reimann et al., 2011; Reimann and

23 Tsukamoto, 2012) indicate that when the stimulation temperature is decreased it becomes easier to 
reset the signal under daylight (although the fading rate also tends to increase). So, by decreasing pIRIR

2 stimulation temperature below $290^{\circ} \mathrm{C}$, we would expect a decrease in equivalent dose because of better signal bleaching but also because of an increase in fading rate.

Figure 8 shows the equivalent doses obtained for sample FER 6, measured using different post

IR-IRSL stimulation temperatures (see Table S1); the preheat temperature was systematically $30^{\circ} \mathrm{C}$ higher than the stimulation temperature, to minimise the risk of any isothermal thermoluminescence

7 signal contributing to the pIRIR signals. Each point is the average of three aliquots. It appears that the equivalent dose increases with stimulation temperature by a factor of $\sim 2$ (corresponding to 90 Gy) between 130 and $290^{\circ} \mathrm{C}$. This is too large to be explained in terms of differential fading; the fading rate is confidently expected to be lower than that for IR at $50^{\circ} \mathrm{C}$ signals, which typically underestimates ages for well-bleached samples by 30\% (e.g., Buylaert et al., 2011; Huntley and Lamothe, 2001). We have measured the corresponding fading rate for the pIRIR 160 signal for three different samples (FER 1, 3 and 6; 6 aliquots each); individual values are indistinguishable and the average fading rate is $2.05 \pm 0.05 \%$ per decade. Thus, we attribute this difference in $D_{e}$ between low and high-temperature pIRIR signals to be mainly due to differential bleaching rates (perhaps arising in part from thermal transfer), although it must be acknowledged that there may also be a contribution from inaccurate measurement. The latter can be identified by e.g., a dose recovery experiment (see below). We also note that the equivalent dose is less sensitive to temperature change at low temperatures (Fig. 8); this supports the possibility that thermal transfer is playing a role.

A dose recovery ratio using the pIRIR ${ }_{160}$ signal was determined by adding a laboratory dose of $103 \mathrm{~Gy}$ on top of the natural dose for 6 aliquots of sample FER 6; after subtracting the natural $D_{\mathrm{e}}(111 \pm$

224 Gy) the measured to given dose ratio was $1.02 \pm 0.05$, confirming the ability of our measurement protocol to accurately determine a laboratory dose given prior to any thermal treatment; we assume 
1 this conclusion also applies to natural doses. We used the $D_{e}$ determined with a pIRIR stimulation

2 temperature of $160^{\circ} \mathrm{C}(111 \pm 4 \mathrm{~Gy})$ to calculate an age (Table 3) of $50 \pm 3$ ka (without correcting for fading

3

4

5

6 or subtracting any residual); this is consistent with the quartz age of $54 \pm 4 \mathrm{ka}$. This agreement further supports the interpretation of Fig. 8 as a bleaching/thermal transfer plateau; the older ages for higher post IR-IRSL stimulation temperatures result from incomplete bleaching, but low temperature signals are better bleached (cf. Fig. 7b, c). The dashed line in Fig. 8 shows predicted equivalent dose derived by multiplying the quartz age by the dose-rate to feldspar; this is the dose expected if the feldspar signal does not fade, was well-bleached at deposition and does not preserve any significant unbleachable residual signal. The possible dose plateau at low stimulation temperatures is $\sim 9 \%$ lower than that expected (rather than the $\sim 20 \%$ lower expected from fading). This may indicate either (i) some residual incomplete bleaching, (ii) inaccurate laboratory estimation of field fading rates (e.g., Wallinga et al., 2007; Reimann et al., 2011), or (iii) the presence of an unbleachable/difficult-to-bleach residual dose. On the latter point, several studies (Madsen et al. 2011; Reimann et al. 2011; Reimann and Tsukamoto 2012) have reported very low residual doses ( $\leq 1 \mathrm{~Gy}$ ) for low temperature pIRIR signals ( $p I R I R_{150}$ and pIRIR $\left.{ }_{180}\right)$. Furthermore, Kars et al. (2014) have shown that experimental determination of such pIRIR residual doses in the laboratory should be treated with caution. In the absence of modern analogues and because we do not intend to use feldspar pIRIR signals for producing an absolute chronology, we have decided to neglect potential residual, unbleachable dose. The average $p|R| R_{160} / q u a r t z$ age ratio (Table 3, Fig. 7c) is $1.08 \pm 0.05(n=8)$ for samples between FER 1 and FER 8 in the stratigraphy, but excluding the outlier FER 2, for which the ratio is $1.97 \pm 0.23$. Since the bleaching of feldspar signals occurs so much more slowly than that of quartz, we deduce that the conclusion above that the quartz signals in FER 6 were well-bleached applies also to all these samples (except FER 2). Because the pIRIR ${ }_{160}$ to quartz age ratios increase below FER 8 (although not to the value recorded by FER 2, Fig. 7c), we cannot with confidence apply this conclusion to the deeper samples. 
In sample FER 2 there is (i) an age inversion observed with multi-grain quartz aliquots, and (ii) an

unusually large ratio of the pIRIR 160 to quartz age. Based on these observations, we suggest that the quartz luminescence signals of FER 2, from Châtelperronian Layer 6, are probably inadequately bleached. This is supported by the micromorphological observations (section 4.1), regarding the nature of Layer 6 and is investigated further in the following.

\subsection{Single grains of quartz}

\subsubsection{Rationale}

If a sample is significantly affected by incomplete bleaching, it is very likely that large multigrain aliquot measurements will result in an overestimate of deposition age, because each aliquot is likely to contain both well-bleached and poorly bleached grains. One approach to determining a more accurate age for the depositional event is to measure individual grains and apply a minimum age model in an attempt to identify those grains most likely to have been well-bleached at burial. As the quartz OSL signal is most readily reset by exposure to light, the likelihood of identifying a well-bleached grain population in an incompletely bleached sample is greater for quartz than for feldspar.

As was discussed above (section 4.2) the comparison of quartz and feldspar multi-grain ages suggested that the quartz signals from samples FER 1, 3, 14, 4, 5, 6, 13 and 8 were all well-bleached, but that the quartz signals from sample FER 2 from the Châtelperronian Layer 6 may not be. Based on the quartz and feldspar comparison alone, we were not able to conclude whether the quartz signals from samples FER 7, 10, 9, 11 and 12 were well-bleached or not. To address these issues in more detail we have measured quartz single grains for six samples (FER 1, 2, 3, 4, 7 and 9) to allow us to compare single grain ages with the other ages and assess the applied methodology more thoroughly. In particular, obtaining a reliable OSL age for sample FER 2 requires single grain measurements and subsequent minimum age modelling to resolve insufficient bleaching. 


\subsubsection{Measurements and rejection criteria}

The SAR protocol (Table S1) employed in these single grain measurements included a post-IR green signal ( $1 \mathrm{~s}$ stimulation with green laser at $125^{\circ} \mathrm{C}$ following a $40 \mathrm{~s}$ stimulation with IR diodes at 125 ${ }^{\circ} \mathrm{C}$; UV detection). The same preheat and cutheat temperatures as for the multi-grain measurements were used. The net signal used in $D_{e}$ calculations was derived from the sum of the OSL in the first $0.05 \mathrm{~s}$ of stimulation minus a background signal (time average of the last $0.2 \mathrm{~s}$ ). Dose response curves were measured up to $200 \mathrm{~Gy}$ for each individual grain. These were fitted with a single saturating exponential function of the form $y=A\left(1-\exp \left(D / D_{0}\right)\right)$ where $y$ is the sensitivity corrected OSL signal, $D$ is the dose, $A$ is the saturated level of the sensitivity-corrected OSL signal and $D_{0}$ is the dose at which $y$ is at $63 \%$ of the saturation level.

The dose estimates from individual grains were accepted based on their sensitivity by selecting only those grains for which the uncertainty on the first test dose signal was less than $20 \%$. Thomsen et al. (submitted) have recently tested the effect of different commonly-employed single grain rejection criteria (e.g., Jacobs et al., 2006; Thomsen et al., 2012) on different samples. They observed that neither the average $D_{e}$ nor the central dose or the overdispersion from the Central Age Model (CAM; Galbraith et al., 1999) vary significantly when grains are rejected based on recycling ratios, recuperation, or IR sensitivity although this process results in a rejection of a great number of grains. We have investigated the effect of these rejection criteria on all analysed samples presumed to have been well-bleached at deposition (cf. Table S3: samples FER 1, 3, 4, 7 and 9). Since these criteria result in the rejection of a significant fraction of grains ( $26 \%$ on average) for no significant effect on $D_{e}$ and OD values (and for no apparent improvement in reliability), these rejection criteria are not employed further in this study.

However, it should also be noted that between 8 and $22 \%$ of the otherwise accepted single grain analyses were deemed to be indistinguishable from saturation. Here we define saturation as a $L_{N} / T_{N}$ 
ratio (L/T ratio for the natural dose cycle) greater than or indistinguishable from the saturation level $(A)$

2 of the laboratory dose response curve. Rejecting a significant fraction of measured grains because of saturation is common, and there is no accepted unbiased method for dealing with such analyses; all reported studies in the literature arbitrarily discard the results from such grains (e.g., Yoshida et al., 2000; Stone and Bailey, 2012; Thomsen et al., 2012); this must lead to a bias, but to an unknown degree. Thomsen et al. (submitted) have recently proposed an additional selection criterion which may provide an unbiased method of rejecting many of such saturated grains. This criterion is based on the ability of a grain to measure the dose of interest, i.e. based on the curvature of the dose response curve (the $D_{0}$ value). Philosophically, this is no different from choosing to use feldspar rather than quartz, because feldspar has a larger $D_{0}$ than quartz. For instance in the probably well-bleached sample FER 1 , it seems very likely that the equivalent dose is 70 Gy. However, for this sample, analysis of single grain dose response curves shows that there are grains with $D_{0}$ values of $<20 \mathrm{~Gy}$ (see Fig. S6). Such grains would be close to $98 \%$ of saturation for a burial dose of $70 \mathrm{~Gy}$. Assuming a typical measurement uncertainty of $>5 \%$ implies that a significant fraction of measurements would be greater than or indistinguishable from saturation and so would be rejected. As a result, the burial dose based on the remaining accepted grains would be underestimated. By only accepting grains with a large $D_{0}$ value the risk of such bias is reduced, although not all saturated grains are removed (see Table S4). We argue that such a selection criterion must introduce less bias than that consisting of rejecting grains because $D_{e}$ is greater than $2 D_{0}$ (as suggested by Wintle and Murray, 2006); indeed, such a rejection is $D_{e}$ dependent and, as such, must lead to some bias. In this study, we begin by only accepting grains with $D_{0}>100 \mathrm{~Gy}$. Application of this criterion reduces the number of grains appearing to be in saturation and systematically increases the burial dose for presumably well bleached samples by $11 \pm 3 \% \quad(n=6)$. The effect of this selection criterion on the dose distributions is shown in Fig. S7 for samples FER 1, 2 and 3 (radial plots are also provided, see Fig. S8) and the implications for age determination are discussed in section 4.5. However, as this $D_{0}$ 
1 criterion has not yet been used extensively in single grain OSL dating, we also report the results

2 obtained without this additional criterion to enable a direct comparison with previously published single

3 grain studies (values in brackets in Table 4).

\subsubsection{Data analysis}

5

Our single grain age determinations make use of methodological results, described elsewhere, concerning dose-rate distributions and their effect on equivalent dose population (Guérin et al., 2015); here we briefly outline the approach and describe the models used, based on the key concept of overdispersion defined as that part of the dispersion in results that cannot be explained by measurement uncertainties.

Three sources of dispersion contribute to the scatter in natural $D_{e}$ distributions: (i) measurement uncertainties (including a $2 \%$ uncertainty per OSL measurement arising from instrument reproducibility; see, e.g., Thomsen et al., 2005; Jacobs et al., 2006); (ii) intrinsic overdispersion, defined as that part of the dispersion in doses observed when measuring a known dose given in the laboratory (e.g., in a dose recovery experiment) that cannot be explained by measurement uncertainty; and finally (iii) extrinsic overdispersion, defined as that part of the dispersion in equivalent doses measured using natural samples that cannot be explained by (i) and (ii). The relative contributions of these sources of dispersion, as well as their characteristics, need to be assessed as part of selecting the most appropriate age model.

Analytical errors on individual dose estimates are, on average, $20 \%$. Fig. S9 shows the relationship between these errors (absolute and relative) and dose estimates. The absolute errors tend to increase as the dose increases, although the correlation is weak. A plot of relative errors against dose shows an even weaker trend, if any. We deduce that our analytical uncertainties tend to have multiplicative error properties, rather than additive (see e.g., Galbraith and Roberts, 2012). Such error properties make models such as the CAM, where the central dose is calculated using a weighted 
1 geometric mean, more appropriate than models such as the $\mathrm{CAM}_{U L}$, where the central dose is estimated

2 using a weighted arithmetic mean. Models such as the latter are suited for distributions where additive error properties explain the dispersion in De measurements (e.g. Galbraith and Roberts, 2012).

We carried out single-grain dose recovery experiments using portions of samples FER 3 and FER

9 that were bleached for $3 \mathrm{~h}$ in a solar simulator (Hönle SOL 2 at a distance of $\sim 80 \mathrm{~cm}$ ) prior to being given gamma doses of 57.6 and $95.4 \mathrm{~Gy}$. The relative intrinsic overdispersion (OD) values for these single dose populations, determined by the CAM were, on average, $12 \%$. To investigate the nature of this intrinsic overdispersion, we analysed the standardised residuals from both the CAM and the CAMUL (see, e.g., Galbraith and Roberts, 2012). In these models, either the same relative or the same absolute error 10 is added in quadrature to analytical uncertainties for each dose estimate. Fig. S10 shows quantile-

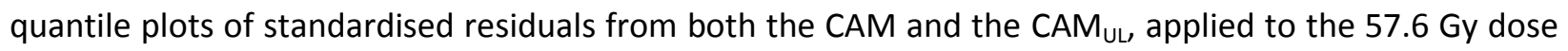

12 recovery $D_{e}$ population from sample FER 3 . The CAM seems to provide a better fit to the data than the 13 CAM $_{U L}$, presumably because the dispersion in estimated $D_{e}$ values is dominated by errors with 14 multiplicative rather than additive properties. We thus consider the CAM best suited to interpret dose 15 recovery tests. The average dose recovery ratio $(1.05 \pm 0.03$; see Table 4$)$ cannot be distinguished from 16 unity at two standard errors; our SAR protocol was thus deemed suitable for all samples. In the natural samples, the measured OD values range between $29 \pm 3 \%$ (FER 1) to $51 \pm 5 \%$ (FER 18 2). The average OD is $35.0 \pm 1.7 \%(n=5)$ excluding FER 2 which is likely to be incompletely bleached. From the quartz and feldspar age comparison, we concluded that the quartz in sample FER 1 to FER 8 (but not

20 including FER 2) were probably well-bleached at deposition, but we were unable to demonstrate that 21 quartz from samples FER 7 and below were well-bleached. However, the OD values determined from the 22 single grain measurements of FER $7(35 \pm 3 \%)$ and FER $9(39 \pm 3 \%)$ are completely consistent with the ODs 
1 determined from the well-bleached samples (FER 1, 3 and 4), we now conclude that the quartz signals

2 from these samples were also probably well-bleached at deposition.

The fact that the average OD of $35 \%$ for natural, well-bleached distributions is significantly

4

greater than the average $\mathrm{OD}$ of $12 \%$ determined in the dose recovery experiments suggests that the main source of dispersion in our well-bleached natural samples is extrinsic. We also applied the CAM and the CAMUL to our natural $D_{e}$ distributions, and Fig. S11 shows a quantile-quantile plot of the standardised residuals from the two models applied to the natural $D_{e}$ population from sample FER 3. Neither of these two models provides a good fit of the data; this suggests that the dispersion in natural $D_{e}$ distributions cannot simply be explained by additional uncertainties with either multiplicative or additive properties.

Given the important contribution of potassium beta dose-rates to total dose-rates, skewed, lognormal distributions can result from the presence of K-feldspar in sediments (e.g., Brennan et al., 1997; Mayya et al., 2006), especially when the average K-content is relatively low ( 0.55-1\%, cf. Table 2$)$. In addition, our samples include a strong sand component with average grain sizes of several $100 \mu \mathrm{m}$, and so the inter-grain distance is not negligible compared to the average range of beta particles in sediments. As a result dose-rate distributions are likely to be an important contribution to origins of the spread in measured $D_{e}$ values; we assume that it is the dominant source of extrinsic dispersion in our natural, well-bleached $D_{e}$ distributions (samples FER 1, 3, 4, 7 and 9). Whatever the nature of the singlegrain dose-rate distribution, it is important to note here that any dose-rate measurements (direct or indirect) provide average dose-rates (arithmetic mean). In cases where dose-rate distributions are an important source of spread in $\mathrm{D}_{e}$ distributions, it is likely that the CAM will underestimate the central dose value; i.e. the dose that must be divided by the measured/calculated average dose-rate (arithmetic mean, which is independent of the nature of the dose-rate distributions) to give an accurate age. As a 
result a CAM dose will underestimate the age, because (i) the CAM provides geometric means

2 (systematically lower than arithmetic means, for any distribution) of $D_{e}$ values and (ii) the weighting of

3 individual estimates by the CAM is dominated by sources of dispersion (in this case, those from dispersions in dose-rate) that have nothing to do with measurement uncertainties (the bigger the extrinsic overdispersion, the closer the CAM result will be to the geometric mean of the dose distribution, irrespective of measurement uncertainties - see last column of Table 4). As a consequence, the presence of two sources of dispersion, each of a different nature argues against the use of models based on either weighted geometric means such as the CAM (because they are not suited to distributions where dose-rate variations explain a large part of the dispersion) or on weighted arithmetic means such as the CAMUL or the IEU models (Thomsen et al., 2007), because they are not suited to distributions displaying multiplicative error properties.

For these reasons, in our $D_{e}$ calculations, we consider it more appropriate to ignore our individual error estimates on $D_{e}$ values derived from individual grains (because they only explain a minor part of the dispersion in our natural distributions); we calculate unweighted, arithmetic means of individual $D_{e}$ estimates (see Thomsen et al., submitted). All single grain ages are listed in Table 3; there is agreement within two standard deviations with the multi-grain results for the well-bleached samples FER 1, 3, 7 and 9 and within three standard deviations for FER 4.

\subsubsection{Minimum age modelling}

A minimum age model was used to interpret the dose distribution of sample FER 2 (Fig. S7); poor-bleaching in this sample appears to have resulted in an OD value $(51 \pm 5 \%)$ considerably greater than those obtained for the well-bleached samples ( $29 \pm 3 \%$ for FER 1 and $35 \pm 3 \%$ for FER 3; see Table 4) directly above and below the sampling location. Furthermore, after selection of grains based on $D_{0}$ values, for sample FER 2, 9 of the otherwise accepted grains (i.e. $9 \%$ of the grains) appeared to be in 
saturation after selection of grains having $D_{0}>100 \mathrm{~Gy}$; this fraction of such rejected grains was much higher than for samples 1, 3 and 4 and further indicates the possibility of poor bleaching (see Table 4).

Given the discussion above on various central age models, there is no obvious model to use for sample FER 2; even the well-bleached portion of the grains from this sample will have a significant overdispersion dominated by extrinsic factors such as dose-rate dispersion. In our case, samples FER 1 and 3 bracket sample FER 2 in stratigraphy. Moreover, the age range is similar since the quartz multigrain ages range from $36.7 \pm 2.0 \mathrm{ka}$ (FER 1 ) to $42.2 \pm 2.8 \mathrm{ka}$ (FER 3). The OD values measured on these well-bleached samples (presumed to arise solely from intrinsic factors and dose-rate heterogeneities) were very similar (32\% on average).

Thus, we have applied the 3 parameter MAM (Galbraith et al., 1999) to the distribution of $D_{e}$ values from FER 2, after selection based on $D_{0}$ values and with an input OD value of $32 \%$. However, the MAM does not fit the data very well as indicated by the log likelihood profiles (Fig. S12). The log likelihood profiles are not symmetrical bell-shaped curves with well-defined $68 \%$ and $95 \%$ confidence intervals, which can be taken as evidence that the resulting OSL age is unreliable (Arnold et al., 2009). Nevertheless, the MAM burial dose estimate of $76.3 \pm 6.7 \mathrm{~Gy}($ at $68 \% \mathrm{Cl}$ ) corresponds to an age of 41.0 $\pm 3.9 \mathrm{ka}$, which is consistent with the chrono-stratigraphy and with other reported ages for Châtelperronian occupations in southwest France (e.g., Hublin et al., 2012).

We have also applied the IEU minimum age model to the same data set. This model has been tested against independent age control, and here we use an $a$ value of 0.32 (this study) and a typical $b$ value of $0.02 \mathrm{~Gy}$ (e.g., Thomsen et al., 2007; Sim et al., 2014; Medialdea et al., 2014). The resulting burial dose for FER 2 is $78.4 \pm 3.5$ Gy (using 76 grains, i.e. $84 \%$ of the total); this gives an age of $42.2 \pm 2.9$ ka, which is in agreement with the MAM age and the chrono-stratigraphy. 
A comparison between quartz and various pIRIR signals has enabled us to identify one poorly-

bleached sample (FER 2) and distinguish it from other surrounding samples. By using pIRIR signals as bleaching proxies in combination with single grain measurements we confirmed that for the remaining samples, the quartz ages obtained from conventional multi-grain measurements were unlikely to be systematically in error because of incomplete bleaching. However, sample FER 2 was probably poorly bleached (which confirms field observations of the corresponding sediment), and required a combination of single grain analysis and minimum age modelling to identify and evaluate the $D_{e}$ of wellbleached grains. As a result, three datasets have been used to derive ages: multi-grain quartz OSL data from both Ris $\varnothing$ and Bordeaux laboratories, and single grain quartz OSL data from the Ris $\varnothing$ laboratory (Fig. 9). The resulting dose estimates were indistinguishable from those samples (FER 1, FER3 and FER 7) for which all three data sets were available, and so a weighted average quartz age has been calculated for each of these samples (Table 3). These ages provide the basis for the discussion in Section 5 of the implications of the chronology of the different occupation Layers of La Ferrassie (Table 6).

\subsection{Radiocarbon ages and overall chronology}

Collagen yield ranges between 2.5 and $4.4 \%$ for the samples listed in Table 5; C:N ratios are well within the accepted range (Van Klinken 1999). The one sample from the Châtelperronian Layer 6 is dated to between 42.4 and $41.3 \mathrm{ka}$ cal BP (95\% confidence interval - $\mathrm{Cl}$ ), whereas three samples from Layer $5 \mathrm{~b}$ provided ages between 44.4 and $47.3 \mathrm{ka}$ cal BP (lower and higher limits of the $95 \% \mathrm{Cl}$ from the three samples).

\subsection{Single grain OSL data analysis in view of radiocarbon results}

Given these radiocarbon results, we can now discuss the appropriateness of our single grain OSL analysis. We first consider the choice between the CAM, the CAM $\mathrm{UL}_{\mathrm{L}}$, the IEU and the unweighted average of $D_{e}$ values in providing the best estimate of the burial dose. For sample FER 3 (the only well- 
bleached sample for which a comparison with radiocarbon is available) the single grain CAM age is 38.1

$2 \pm 2.2 \mathrm{ka}$, the single grain $\mathrm{CAM}_{\mathrm{UL}}$ age $37.8 \pm 2.2 \mathrm{ka}$, and the IEU age $38.4 \pm 2.6 \mathrm{ka}$. None of these are

3 consistent (95\% confidence) with the ${ }^{14} \mathrm{C}$ age range. In contrast our preferred unweighted average of $D_{e}$ values gives an age of $40.9 \pm 3.1$ ka (see Table 3 ), which is consistent ( $95 \%$ confidence) with the radiocarbon ages. This supports our contention that none of the more statistically robust models (CAM, $\left.\mathrm{CAM}_{U L}, \mathrm{IEU}\right)$ offer an appropriate treatment of distributions where both multiplicative error properties and important dose-rate (i.e., true dose) variations contribute to the scatter in measured $D_{e}$ values.

Even though we have no radiocarbon age to compare with the single grain OSL age of sample FER 1, it is interesting to note that the ages obtained with the CAM $(36.6 \pm 2.0 \mathrm{ka})$, the CAM $(35.6 \pm 1.9$ ka) and the IEU $(35.7 \pm 2.1 \mathrm{ka})$ are systematically younger than that based on the age derived from the unweighted arithmetic mean of $D_{e}$ values $(38.4 \pm 2.5 \mathrm{ka})$.

The minimum ages obtained for sample FER 2 using the MAM or the IEU cannot be distinguished (95\% confidence) from the ${ }^{14} \mathrm{C}$ age range of 42.40 to $41.25 \mathrm{cal} \mathrm{BP}$ ka (95 \% Cl). It is difficult to choose which minimum age model provides the most accurate age; however, because (i) the likelihood profiles obtained with the MAM (Fig. S12) do not appear very satisfactory, (ii) the age uncertainty obtained with the IEU is smaller than with the MAM, and (iii) the IEU age is closer to the ${ }^{14} \mathrm{C}$ age, in Table 3 the single grain age of FER 2 is that obtained with the IEU. The excellent agreement between the IEU age and the ${ }^{14} \mathrm{C}$ available leads us to formulate the hypothesis that for this particular sample, poor-bleaching is the dominant factor of dispersion in measured $D_{e}$ values. Even though the IEU does not seem to handle the dispersion factors for well-bleached samples, it seems to give a reliable age estimate for the poorlybleached sample FER 2.

The second analytical approach that can be tested by comparison with ${ }^{14} \mathrm{C}$ is the use of a selection criterion based on the curvature parameter $\left(D_{0}\right)$ of laboratory dose-response curves, and in 
particular the choice of a value for this parameter which selects only those grains that are able to record the full range of doses recorded in the sediment. Table S4 lists the results obtained for two of the three uppermost samples in the stratigraphy: FER 2 and 3 (unweighted averages of $D_{e}$ values and corresponding ages for sample FER 3; IEU doses and ages for poorly-bleached sample FER 2). These are the only two samples with independent ${ }^{14} \mathrm{C}$ age control. As expected there is a systematic increase in age for both samples (FER 2: 18\%; FER 3: 8\%) using the $D_{0}>100$ Gy criterion. However, the equivalent dose does not depend significantly on $D_{0}$ values $>60 \mathrm{~Gy}$. Furthermore, for all $D_{0}$ values between 80 and $120 \mathrm{~Gy}$, the single-grain OSL ages for samples FER 2 and 3 are in agreement with the available radiocarbon ages (one exception to that rule is for $D_{0}>120 \mathrm{~Gy}$, where the age of FER 3 is not consistent with the greatest radiocarbon age of sample S-EVA 26506, but is consistent with the other two radiocarbon ages from Layer $5 b$ ). We conclude that (i) without applying this $D_{0}$ criterion the single grain quartz OSL ages would underestimate the expected age based on ${ }^{14} \mathrm{C}$ and (ii) this statement is independent of the chosen value of $\mathrm{D}_{0}$ between 80 and $120 \mathrm{~Gy}$. This supports our a priori argument that the $D_{0}>100$ Gy selection criterion is necessary and provides an unbiased approach to reject most of the saturated grains. This also seems to confirm that these low $D_{0}$ grains are not capable of recording the dose range required to calculate an accurate age for these samples.

\section{Discussion of the ages and implications}

The OSL data suggest the following chronology for the La Ferrassie sequence: Layer 1 was deposited during MIS 5 (most likely 5b), around $90 \mathrm{ka}$ (even though the overestimation of this age by pIRIR 160 signals leaves room for an underestimation of the deposition age by quartz OSL, arising from saturation effects in the quartz OSL signals), and Layer 2 during MIS 4 with ages ranging from $74 \pm 5$ to $62 \pm 4 \mathrm{ka}$. The ice segregation and cryoturbation patterns identified in Layer 2 and at the top of Layer 1 seem consistent with the deposition of Layer 2 during MIS 4. Layer 3 was deposited during MIS 3 
between $57 \pm 3$ and $44 \pm 3$. From a chronological point of view, Layer 4 is indistinguishable with ages of $54 \pm 4$ and $44 \pm 3 \mathrm{ka}$. Layer 5 yielded three statistically indistinguishable OSL ages with an average of $43 \pm$ $3 \mathrm{ka}$, which is consistent with the radiocarbon results (from 47.3 to $44.4 \mathrm{ka} \mathrm{BP)}$. Application of a minimum age model to the single-grain quartz OSL dose distribution gives an age of $42 \pm 3$ ka for Layer 6; this OSL age is indistinguishable from the radiocarbon age of between 42.4 and $41.3 \mathrm{ka}$ cal $\mathrm{BP}(95 \% \mathrm{Cl})$ from the same layer and also compares well with radiocarbon ages obtained recently for the same industry from the Grotte du Renne in Arcy-sur-Cure and from Saint-Césaire (Hublin et al., 2012; see also Mercier et al., 1991). The agreement between single-grain OSL and radiocarbon data for this layer

9 indicates, a posteriori, that there was, indeed, most likely a portion of the quartz grains from sample FER 2 which were sufficiently exposed to sunlight to have their OSL reset signal prior to deposition. Finally,

11 Layer 7 is dated to $37 \pm 2 \mathrm{ka}$. This age also agrees well with the Aurignacian attribution of this layer

12 (Banks et al., 2013, and references therein). Taxa associated with cold climate conditions (reindeer, woolly mammoth, or woolly rhinoceros) occur throughout the sequence (with the exception of Layer 4) and are dominant in Layers 6 and 7 (reindeer only). Thus it could be that Layers 6 and 7 correspond to one of the cold events of MIS 3. Taxa associated with warmer environments (especially roe deer) are found in Layers $5 \mathrm{~b}$ and below. Layer 2, associated with MIS 4, preserves a significant number of taxa

17 adapted to temperate conditions (in particular, higher abundance of roe deer over reindeer) - which can

18 be linked with, e.g., the Roc de Marsal sequence where the fauna attributed via TL and OSL dating to 19 MIS 4 also shows diversity in taxa (Guérin et al., 2012). Further refinement of the chronology of the upper part of the sequence using radiocarbon is ongoing. These data are all summarized in Fig. 9 and

21 Table 6. These ages add to the growing database for late Middle Paleolithic sites in southwest France 23 (e.g. Guibert et al., 2008) and to the long-debated question of whether lithic variability in these sites follows chronological patterns (Mellars 1969). The variability organized into the so-called Mousterian 
facies (e.g. Ferrassie Mousterian, MTA, etc.) consists of three main axes: (i) whether blank production is

2 dominated by Levallois techniques or Quina techniques, (ii) how common scrapers are among the retouched tools; and (iii) the presence or lack of, typically, cordiform bifaces. Prior to the development of absolute dating techniques applicable to this time period, Mellars $(1969,1996)$ noted that (a) in stratigraphic successions scraper-rich industries (Ferrassie and Quina Mousterian) occur below the MTA, (b) the scraper-rich industries which Levallois technology (Ferrassie Mousterian) gives way to later Quina techniques, and (c) MTA assemblages are at the top of the sequence and are frequently immediately under the Châtelperronian (further suggesting that MTA represents the final Mousterian). However, more recent efforts to re-evaluate existing ages and to re-date the sites of southwest France have not fully supported this model and have instead shown that scraper rich industries (Quina Mousterian) overlap - within uncertainties - with those with few scrapers (Denticulate Mousterian) and that bifacial industries (MTA) overlap with both of these (Guibert et al., 2008; Richter et al., 2013a).

The base of the La Ferrassie stratigraphic sequence does not contradict the Mellars' stratigraphic model because the bifacial assemblages found there under the Ferrassie Mousterian have not been previously considered either Acheulian or MTA (cf. Mellars, 1969:167). Typically in southwest France the Acheulian is older and the MTA is younger (Soressi et al., 2007; Guibert et al., 2008; Vieillevigne et al., 2008; McPherron et al., 2012; Richter et al., 2013) than the ages reported here. However, aside from these two techno-complexes, bifaces occur at a larger geographical scale throughout the Middle Palaeolithic (Monnier, 2006; Ruebens, 2012). This is especially true of northern France where bifacial industries tend to date to MIS 5 (see review in Ruebens, 2012). Thus the La Ferrassie ages from the lower levels suggest more variability in the late Middle Palaeolithic of South West France than the Mousterian facies framework considers. A more precise characterization of the La Ferrassie biface assemblages and their affinities with other known bifacial industries is work ongoing. 
The age of the Ferrassie Mousterian levels at La Ferrassie raises even more questions. Given

that the overlying Châtelperronian is increasingly well constrained elsewhere to no earlier than approximately $45 \mathrm{ka}$ (Hublin et al., 2012), it seems that these Ferrassie layers at La Ferrassie are indeed quite late in the Middle Palaeolithic of southwest France. Scraper-rich industries based on Levallois technology have remained outside recent dating efforts (e.g. Guibert et al., 2008) probably because they are relatively rare in southern France and virtually all examples of it come from relatively old excavations with sometimes questionable stratigraphic contexts. Examples include Abri Chadourne (Bordes et al., 1954), Caminade (Sonneville-Bordes and Montureux, 1955), Pech de Bourre (Peyrony, 1942), Roc en Pail (Gruet, 1969; 1984), and Petit Puymoyen (Favraud, 1908). There are also four examples of Ferrassie Mousterian layers from Bordes' excavations at Combe Grenal. That said, the new results from the eponymous site of La Ferrassie suggest that the layers in question are chronologically indistinguishable from what has been previously reported for Denticulate Mousterian, MTA, and for most of Quina Mousterian (Soressi et al., 2007; Guibert et al., 2008; Vieillevigne et al., 2008; McPherron et al., 2012; Richter et al., 2013a, b), meaning that a scraper-rich industry with Levallois technology is also part of late Middle Palaeolithic variability. Further, the age of Layer 5 of La Ferrassie is younger than the ages determined for the Quina Layer SW-US22 from Chez Pinaud-Jonzac (TL on heated flints: $73 \pm 8$ ka, Richter et al., 2013b). Thus, in view of these radiometric dating results, it seems that the hypothesis of a regional stratigraphy where Quina Mousterian always precedes Ferrassie Mousterian does not hold against chronological information.

One alternative possibility is that the Mousterian in Layers 4 and 5 at La Ferrassie - thus far recognised as Ferrassie Mousterian - is not actually a Ferrassie Mousterian. Older collections such as that from La Ferrassie can have significant excavator bias, meaning that particular pieces were preferentially saved. At Combe-Capelle Bas, for example, new excavations (Dibble and Lenoir 1995:168170) showed that the 1930 s collections favoured scrapers over notches and denticulates. The same 
could have easily happened at La Ferrassie. Our collections are at present limited, and so a better

2 understanding of the significance of the young age of these deposits for models of Mousterian stone

3 tool variability will have to wait for a more extensive excavation to generate a sufficient sample for a

4 proper characterization of the lithics (currently $<1 \mathrm{~m}^{2}$ has been excavated).

Finally, the ages reported here provide a chronological context for the La Ferrassie 2 skeleton.

6 According to the original excavators and our recent analysis of the sediments attached to the foot in

7 comparison with those from our stratigraphic section, the LF 2 skeleton - and most likely LF 1, which was found $50 \mathrm{~cm}$ east of La Ferrassie 2 (cf. section 2.4) - was found in one of the Ferrassie Mousterian

9 layers; whether it was in our Layer 4 or 5 remains unclear at this stage, but this still provides

10 chronological information. The oldest OSL age for Layer 4 provides a Terminus Post Quem: the LF 2

11 skeleton is not older than $54 \pm 4$ ka and can now be placed in the final Mousterian of southwest France,

12 most likely around $44 \pm 3$ (top of Layer 4 ) or $43 \pm 3$ (Average of individual ages from Layer 5).

It is likely that this age also applies to the La Ferrassie 1 skeleton. The age of the remaining

14 skeletal material uncovered at the site, however, remains unknown. Though the archaeological

15 sequences of the east section preserved today at La Ferrassie and our own sequence are the same and

16 although Peyrony and Capitan reported a consistent stratigraphy across the site, it is clear from our on-

17 going analysis that there were two different sources for the sediments in the western versus the eastern

18 portions of the entire cave complex, i.e. for the sediments of our excavations at the entrance to La

19 Ferrassie, and for those of Peyrony and Delporte further inside the cave. Thus, until strong arguments

20 can be made to place each of these Neanderthals in one depositional context or the other, it would be

21 premature to discuss their possible age.

\section{6. Conclusion}


Luminescence dating methods have been applied to sediment samples from the entire stratigraphic sequence of La Ferrassie. The comparison between quartz OSL and feldspar post-IR IRSL measurements, at various stimulation temperatures, on multi-grain aliquots has indicated that the quartz OSL signal from all samples but one (FER 2, from the Châtelperronian layer) was well-bleached at the time of deposition and thus can provide reliable chronological data. Single grain OSL measurements were undertaken on sample FER 2, and on adjacent well-bleached samples, to investigate the sources of dispersion in the equivalent dose distributions. Finally, a preliminary set of radiocarbon ages has shown excellent agreement with OSL ages for the youngest Ferrassie Mousterian in the sequence and for the

9 Châtelperronian layer, thus confirming the accuracy of our OSL age modelling at La Ferrassie (and the relative inaccuracy of models not taking dose-rate variations into account, at least for well-bleached

11 samples).

The presence of bifaces in a Mousterian industry, at the base of the sequence, has been dated to the MIS 5 (most likely 5b), the MIS 4 and the MIS 3, which in the first two cases is rather unusual for cave sites in southwest France and in particular older than dated occurrences of MTA in the area. The

15 Ferrassie Mousterian layers have been dated to the MIS 3 (between $54 \pm 4$ and $40 \pm 2 \mathrm{ka}$ ) and thus appear quite late in the Middle Palaeolithic of the region; these chronological results both suggest

17 additional complexity in late Mousterian variability. The La Ferrassie 1 and 2 skeletons, which have been attributed to one of these Ferrassie Mousterian layers, are most likely dated to $\sim 43-45 \mathrm{ka}$ and are no older than $54 \pm 4 \mathrm{ka}$. The upper part of the Ferrassie Mousterian layer is chronologically

20 indistinguishable from the Châtelperronian layer ( $42 \pm 3 \mathrm{ka})$, which seems to be contemporaneous of

21 other Châtelperronian assemblages in the region. Finally, the Aurignacian Layer is dated to $37 \pm 2$ ka.

\section{Acknowledgements}


This work was supported by a H.C. Ørsted postdoctoral grant awarded by The Technical University of Denmark to GG. The financial supports of Région Aquitaine, Conseil Général de Dordogne, INRAP, National Science Foundation, University of California, Davis, Max Planck Society, Leakey Foundation,

French National Research Agency (Project number ANR-10-LABX-52) via the LaScArBs Labex, University

Research Foundation of the University of Pennsylvania, are also acknowledged. The authors are grateful to two anonymous reviewers for constructive and useful comments on an earlier version of this article.

\section{References}

Aitken, M. J., 1985. Thermoluminescence dating. Academic Press, London.

Arnold, L.J., Roberts, R.G., Galbraith, R.F., DeLong, S.B., 2009. A revised burial dose estimation procedure 10 for optical dating of young and modern-age sediments. Quaternary Geochronology, 4, 306-325.

11 Bar-Yosef, O., 1988. Evidence for Middle Palaeolithic symbolic behaviour: a cautionary note. In: Otte, M. 12 (Ed.), L'Homme de Neanderthal. La Pensée, vol. 5. ERAUL 32, Liège, pp. 11-16.

13 Binant, P., 1991a. La Préhistoire de la mort. Paris : éd. Errance, 170 p.

14 Binant, P., 1991b. Les sépultures du Paléolithique. Paris : éd. Errance, 108 p.

15 Bordes, F. 1957. La classification du Moustérien: état actuel. In Lexique Stratigraphique International 16 (Europe), vol. 1., 73-77.

17 Bordes, F., 1961. Moustérien Cultures in France. Science 134 (3482), 803-810.

18 Bordes, F., Fitte, P., Blanc, S., 1954. L'abri Armand Chadourne. Bulletin de la Société Préhistorique 19 Française, t. LI, 5-6, 229-54.

20 Bortolot, V.J., 2000. A new modular high capacity OSL reader system. Radiation Measurements 32, 75121757.

22 Bos, A.J.J., Wallinga, J., Johns, C., Abellon, R.D., Brouwer, J.C., Schaart, D.R., Murray, A.S., 2006. Accurate 23 calibration of a laboratory beta particle dose-rate for dating purposes. Radiation Measurements 41, 24 1020-1025.

25 Brennan, B. J., Schwarcz H. P., Rink J., 1997. Simulation of the gamma radiation field in lumpy 26 environments. Radiation Measurements 27, 2, 299-305.

27 Breuil H., 1921. Communication sur les squelettes de La Ferrassie, L'Anthropologie, 31, 342-344.

28 Bronk Ramsey, C., Lee, S., 2013. Recent and planned developments of the program OxCal, Radiocarbon, 29 55, 3-4. 
Brown, T.A., Nelson, D.E., Vogel, J.S., Southon, J.R., 1988. Improved Collagen Extraction by modified Longin method, Radiocarbon 30, 171 - 177.

Buylaert J.-P., Murray A.S., Thomsen K.J., Jain M., 2009. Testing the potential of an elevated temperature IRSL signal from K-feldspar. Radiation Measurements 44, 560-565.

Buylaert, J.P., Huot, S., Murray, A.S. \& Van den haute, P., 2011. Infrared stimulated luminescence dating of an Eemian (MIS 5e) site in Denmark using K-feldspar. Boreas, 40, 46-56.

Buylaert, J.-P., Jain, M., Murray, A.S., Thomsen, K.J., Thiel, C., Sohbati, R., 2012. A robust feldspar luminescence dating method for Middle and Late Pleistocene sediments. Boreas 41, 435-451.

Bøtter-Jensen, L., Bulur, E., Duller, G.A.T., Murray, A.S., 2000. Advances in luminescence instrument systems. Radiation Measurements 32, 523-528.

Bøtter-Jensen, L., Andersen, C.E., Duller, G.A.T., Murray, A.S., 2003. Developments in radiation, stimulation and observation facilities in luminescence measurements. Radiation Measurements 37, 535541.

B $\varnothing$ tter-Jensen, L., Thomsen, K.J., Jain, M., 2010. Review of optically stimulated luminescence (OSL) instrumental developments for retrospective dosimetry. Radiation Measurements 45, 253-257.

Capitan, L., Peyrony, D., 1909. Deux squelettes humains au milieu des foyers de l'époque moustérienne. Revue de l'Ecole d'Anthropologie de Paris, 19, 402-409.

Capitan, L., Peyrony, D., 1910. Deux squelettes humains au milieu des foyers de l'époque moustérienne. Bulletins et mémoires de la Société d'Anthropologie de Paris, t. I, IV, 48-53.

Capitan L., Peyrony D., 1912. Station préhistorique de La Ferrassie, commune de Savignac-du-Bugue (Dordogne). Revue anthropologique 2, 76-99.

Capitan L., Peyrony D., 1921a. Découverte d'un sixième squelette moustérien à La Ferrassie (Dordogne). Revue Anthropologique 31, 382-388.

Capitan, L., Peyrony, D., 1922. Station préhistorique de la Ferrassie. Revue Anthropologique 22, 76-99.

Chase, P. G., Dibble, H. L., 1987. Middle Palaeolithic symbolism: a review of current evidence and interpretations. Journal of Anthropological Archaeology 10, 193-214.

Cunningham, A.C., Wallinga, J., 2010. Selection of integration time intervals for quartz OSL decay curves. Quaternary Geochronology 5, 657-666.

Delporte, H., 1984. Le grand abri de La Ferrassie. Fouilles 1968-1973. Etudes Quaternaires n7, Laboratoire de Paléontologie Humaine, Paris, 277 p.

Deufleur, A., 1993. Les sépultures moustériennes. Paris : CNRS éd., 325 p.

Dibble, H.L., Lenoir, M. (Eds.), 1995. The Middle Paleolithic Site of Combe-Capelle Bas (France). The University Museum Press, Philadelphia, $386 \mathrm{p}$. 
Duday, H., Courtaud, P., Crubezy, E., Sellier, P., Tillier, A.-M., 1990. L'anthropologie "de terrain" : reconnaissance et interprétation des gestes funéraires. Bulletins et Mémoires de la Société d'Anthropologie de Paris 2, 29-50.

Duller, G.A.T., 2003. Distinguishing quartz and feldspar in single grain luminescence measurements. Radiation Measurements 37, 161-165.

Duller, G.A.T., 2007. Analyst. Manual, 1-45.

Duller, G.A.T., Bøtter-Jensen, L., Murray, A.S., Truscott, A.J., 1999. Single grain laser luminescence (SGLL) measurements using a novel automated reader. Nuclear Instruments and Methods B 155, 506-514.

Favraud, A., 1908. La station moustérienne du Petit-Puymoyen, commune de Puymoyen (Charente). Revue de l'Ecole d'Anthropologie de Paris 18, t. II., 46-66.

Galbraith R.F., Roberts R.G., Laslett G.M., Yoshida H., Olley J.M., 1999. Optical dating of single and multiple grains of quartz from Jinmium rock shelter, northern Australia: Part I, experimental design and statistical models. Archaeometry 41, 339-364.

Galbraith, R.F., Roberts, R.G., 2012. Statistical aspects of equivalent dose and error calculation and display in OSL dating: an overview and some recommendations. Quaternary Geochronology 11, 1-27.

Gargett, R. H., 1989. Grave shortcomings. The evidence for Neanderthal burial. Current Anthropology 30, 157-177.

Gargett, R. H., 1999. Middle Palaeolithic burial is not a dead issue: the view from Qafzeh, Saint-Cesaire, Kebara, Amud, and Dederiyeh. Journal of Human Evolution 37, 27-90.

Godfrey-Smith, D.L., Huntley, D.J., Chen, W.H., 1988. Optically dating studies of quartz and feldspar sediment extracts. Quaternary Science Reviews 7, 373-380.

Gruet, M. 1969. Livret guide de l'excursion C 6, Bretagne-Anjou. VIIIe Congrès INQUA; 9e et 10e journées, Bordeaux, 68-79.

Gruet, M., 1984. L'apport de deux sites angevins à la chronologie des terrasses fluviales : Roc-en-Pail et Port-Launay. Bulletin de l'Association Française d'Etudes du Quaternaire, 21, 13-18.

Guérin, G., Mercier, N., 2011. Determining gamma dose-rates by field gamma spectroscopy in sedimentary media: results of Monte Carlo simulations. Radiation Measurements 46, 190-195.

Guérin, G., Mercier, N. and Adamiec, G, 2011. Dose-rate conversion factors: update. Ancient TL 29, 5-8.

Guérin, G., Mercier, N., 2012. Preliminary insight into dose deposition processes in sedimentary media on a grain scale: Monte Carlo modelling of the effect of water on gamma dose-rates. Radiation Measurements, 47, 541-547.

Guérin, G., Discamps, E., Lahaye, C., Mercier, N., Guibert, P., Turq, A., Dibble, H., McPherron, S., Sandgathe, D., Goldberg, P., Jain, M., Thomsen, K., Patou-Mathis, M., Castel, J.-C., Soulier, M.-C., 2012a. Multi-method (TL and OSL), multi-material (quartz and flint) dating of the Mousterian site of the Roc de Marsal (Dordogne, France): correlating Neanderthals occupations with the climatic variability of MIS 5-3. Journal of Archaeological Science, 39, 3071-3084. 
Guérin, G., Mercier, N., Nathan R., Adamiec, G., Lefrais, Y., 2012b. On the use of the infinite matrix assumption and associated concepts: a critical review. Radiation Measurements, 47, 778-785.

Guérin, G., Jain M., Thomsen K. J., Murray A. S., Mercier, N., 2015. Modelling dose rate to single grains of quartz in well-sorted sand samples: the dispersion arising from the presence of potassium feldspars and implications for single grain OSL dating. Quaternary Geochronology 27, 52-65.

Guibert, P., Bechtel, F., Bourguignon, L., Brenet, M.,Couchoud, I., Delagnes, A.,Delpech, F., Detrain, L., Duttine, M., Folgado, M., Jaubert, J., Lahaye, C., Lenoir, M., Maureille, B., Texier, J.-P., Turq, A.,Vieillevigne, E., Villeneuve, G., 2008. Une base de données pour la chronologie du Paléolithique moyen dans le Sud-Ouest de la France. Mémoire XLVII de le Société Préhistorique Française, 19-40.

Harrold, F.B., 1980. A comparative analysis of Eurasian Palaeolithic burials. World Archaeology 12, 195211.

Heim J.-L., 1968. Les restes neanderthaliens de La Ferrassie I. Nouvelles donnees sur la stratigraphie et inventaire des squelettes. Comptes Rendus hebdomadaires de l'Académie des Sciences, Paris, 266, 576578.

Heim J.-L., 1976. Les hommes fossiles de La Ferrassie. Tome I. Archives de l'Institut de Paléontologie Humaine, 35. Paris : Masson, $331 \mathrm{p}$.

Heim J.-L., 1982a. Les enfants néandertaliens de La Ferrassie. Fondation Singer Polignac. Paris : Masson, $169 \mathrm{p}$.

Heim J.-L., 1982b. Les hommes fossiles de La Ferrassie. Tome II. Archives de I'Institut de Paléontologie Humaine, 38. Paris : Masson, $272 \mathrm{p}$.

Higham, T.F.G., Jacobi, R.M., Ramsey, C.B., 2006. AMS radiocarbon dating of ancient bone using ultrafiltration, Radiocarbon 48, 179-195.

Higham, T., Brock, F., Peresani, M., Broglio, A., Wood, R., Douka, K., 2009. Problems with radiocarbon dating the Middle to Upper Palaeolithic transition in Italy. Quaternary Science Reviews, 28, 1257-1267.

Hublin, J.-J., Talamo, S., Julien, M., David, F., Connet, N., Bodu, P., Vandermeersch, B. and M.P. Richards, 2012. Radiocarbon dates from the Grotte du Renne and Saint-Césaire support a Neanderthal origin for the Châtelperronian. Proceedings of the National Academy of Sciences of the United States of America. 109, 18743-18748.

Huntley, D.J., Baril, M.R., 1997. The K content of the K-feldspar being measured in optical dating or in thermoluminescence dating. Ancient TL 15, 11-13.

Huntley, D.J., Hancock, R.G.V., 2001. The Rb contents of the K-feldspar grains being measured in optical dating. Ancient TL 19, 43-46.

Huntley D.J., Lamothe M., 2001. Ubiquity of anomalous fading in K-feldspar and the measurement and correction for it in optical dating. Canadian Journal of Earth Sciences 38, 1093-1106.

Jacobs, Z., Duller, G.A.T., Wintle, A.G., 2006. Interpretation of single grain $D_{e}$ distributions and calculation of $D_{\mathrm{e}}$. Radiation Measurements, 41, 264-277. 
Jacobs Z., Wintle A.G., Roberts R.G., Duller G.A.T., 2008. Equivalent dose distributions from single grains of quartz at Sibudu, South Africa: context, causes and consequences for optical dating of archaeological deposits. Journal of Archaeological Science 35, 1808-1820.

Jain M., Ankjærgaard C., 2011. Towards a non-fading signal in feldspar: Insight into charge transport and tunnelling from time-resolved optically stimulated luminescence. Radiation Measurements 46, 292-309.

Kars, R. H., Reimann, T., Ankjærgaard, C., Wallinga, J., 2014. Bleaching of the post-IR IRSL signal: new insights for feldspar luminescence dating. Boreas 43, 780-791.

Klinken, G. J. v., 1999. Bone Collagen Quality Indicators for Palaeodietary and Radiocarbon Measurements. Journal of Archaeological Science, 26, 687-695.

Langley, M.C., Clarkson, C., Ulm, S., 2008. Behavioral complexity in Eurasian Neanderthal populations: a chronological examination of the archaeological evidence. Cambridge Archaeological Journal 18, 289-

12307.

13 Lapp, T., Jain, M., Thomsen, K. J., Murray, A. S. \& Buylaert, J. P., 2012. New luminescence measurement facilities in retrospective dosimetry. Radiation Measurements 47, 803-808.

15 Laville D., 2007. La Ferrassie : taphonomie d'un site sépulcral moustérien. Mémoire de Master, 16 Université de Liège, 2 volumes, $118 \mathrm{p}$.

17 Lindly, J.M., Clark, G.A., 1990. Symbolism and modern human origins. Current Anthropology 31, 23318261.

Longin, R., 1971. New method of collagen extraction for radiocarbon dating, Nature 230, 241-242.

Madsen, A.T., Buylaert, J.P., Murray, A.S., 2011. Luminescence dating of young coastal deposits from

21 New Zealand using Feldspar. Geochronometria 38, 378-390.

Maureille B., Vandermeersch B., 2007. Les sépultures néandertaliennes. In, Vandermeersch B. et Maureille B., 2007 (Eds.), Les Néandertaliens, biologie et cultures. Documents préhistoriques 23, Paris : C.T.H.S, pp. 311-322.

Mayya Y.S., Morthekai P., Murari M.K. Singhvi, A.K., 2006. Towards quantifying beta microdosimetric effects in single-grain quartz dose distribution. Radiation Measurements 41, 1032-1039.

McPherron, S.P., Talamo, S., Goldberg, P., Niven, L., Sandgathe, D., Richards, M.P., Richter, D., Turq, A., Dibble, H.L., 2012. Radiocarbon Dates for the Late Middle Palaeolithic at Pech de l'Azé IV, France. Journal of Archaeological Science, 39, 3436-3442.

Medialdea, A., Thomsen, K.J., Murray, A.S., Benito, G, 2014. Reliability of equivalent-dose determination and age-models in the OSL dating of historical and modern palaeoflood sediments. Quaternary

32 Geochronology 22, 11-24.

33 Mejdahl V. 1979. Thermoluminescence dating: beta-dose attenuation in quartz grains. Archaeometry 21, $34 \quad 61-72$.

Mejdahl V. 1987. Internal radioactivity in quartz and feldspar grains. Ancient TL, 5, 10-17. 
Mellars, P., 1969. The chronology of Mousterian industries in the Périgord region of southwest France.

2 Proceedings of the Prehistoric Society 35, 134-171.

3 Mellars, P., 1996. The Neanderthal Legacy. Princeton, NJ: Princeton University Press.

4 Mercier, N., Valladas, H., Joron, J.-L., Reyss, J.-L., Lévêque, F., Vandermeersch, B., 1991.

5 Thermoluminescence dating of the late Neanderthal remains from Saint-Césaire (France). Nature 351,

6 737-739.

7 Monnier, G. F., 2006. The Lower/Middle Palaeolithic Periodization in Western Europe: An Evaluation.

8 Current Anthropology, 47, 709-744.

9 Murray, A. S., Wintle, A. G., 2000. Luminescence dating of quartz using an improved single-aliquot

10 regenerative-dose protocol. Radiation Measurements 32, 57-73.

11 Murray, A. S., Wintle, A. G., 2003. The single aliquot regenerative dose protocol: potential for 12 improvements in reliability. Radiation Measurements 37, 377-381.

13 Murray, A.S., Thomsen, K.J., Masuda, N., Buylaert, J.P., Jain, M., 2012. Identifying well-bleached quartz 14 using the different bleaching rates of quartz and feldspar luminescence signals. Radiation 15 Measurements 47, 688-695.

Nathan R. P., 2011. Numerical modelling of the environmental dose-rate for trapped charge dating.

17 Unpublished PhD thesis, University of Oxford.

18 Nathan R.P., Mauz, B., 2008. On the dose-rate estimate of carbonate-rich sediments for trapped charge dating. Radiation Measurements 43, 14-25.

Olley, J.M., Pietsch, T., Roberts, R.G., 2004. Optical dating of Holocene sediments from a variety of geomorphic setting using single grains of quartz. Geomorphology, 60, 337-358.

Pettitt, P.B., 2002. The Neanderthal dead: exploring mortuary variability in Middle Paleolithic Eurasia.

23 Before Farming 1, 1-26.

24 Peyrony, D., 1921. Les Moustériens inhumaient-ils leurs morts. Périgueux : Ribes et Cie, 8 p.

25 Peyrony, D.,1934. La Ferrassie: Moustérien, Périgordien, Aurignacien. Préhistoire, E. Leroux, Paris, t. III, $26151 \mathrm{p}$.

27 Peyrony, D.,1942. Station préhistorique du Pech-de-Bourre. Commune de Prats-de-Carlux (Dordogne).

28 Bulletins de la Société Historique et Archéologique du Périgord, sept. -oct., 289-297.

Prescott, J.R., Hutton, J.T., 1988. Cosmic ray and gamma ray dosimetry for TL and ESR. Nuclear Tracks and Radiation Measurements, 14, 223-227.

31 Readhead, M.L., 2002. Absorbed dose fraction for ${ }^{87} \mathrm{Rb}$ beta particles. Ancient TL 20, 25-28.

32 Reimann, T., Tsukamoto, S., Naumann, M., Frechen, M., 2011. The potential of using K-rich feldspar for 33 optical dating of young coastal sediments - a test case from Darss-Zingst peninsula (southern Baltic Sea 34 coast). Quaternary Geochronology 6, 207-222. 
Reimann, T., Tsukamoto, S., 2012. Dating the recent past ( $<500$ years) by post-IR IRSL feldspar Examples from the North Sea and Baltic Sea coast, Quaternary Geochronology 10, 180-187.

Reimer, P.J., Bard, E., Bayliss, A., Beck, J.W., Blackwell, P.G., Bronk Ramsey, C., Brown, D.M., Buck, C.E., Edwards, R.L., Friedrich, M., Grootes, P.M., Guilderson, T.P., Haflidason, H., Hajdas, I., Hatte,, C., Heaton, T.J., Hogg, A.G., Hughen, K.A., Kaiser, K.F., Kromer, B., Manning, S.W., Reimer, R.W., Richards, D.A, Scott, E.M., southon, J.R., Turner, C.S.M., van der Plicht, J., 2013. Selection and Treatment of data for radiocarbon calibration: An update to the International Calibration (INTCAL) Criteria. Radiocarbon, 55 (4), 1-23.

Richter, D., Tostevin, G., Škrdla, P., Davies, W., 2009. New radiometric ages for the Early Upper Palaeolithic type locality of Brno-Bohunice (Czech Republic): comparison of OSL, IRSL, TL and 14C dating results. Journal of Archaeological Science 36, 2009, 708-720.

Richter, D., Dombrowski, H., Neumaier, S., Guibert, P., Zink, A., 2010a. Environmental gamma dosimetry for in-situ sediment measurements by OSL of a-Al2O3:C. Radiation Protection Dosimetry 141, 27-35.

Richter, D., Dibble, H., Goldberg, P., McPherron, S.P., Niven, L., Sandgathe, D., Talamo, S., Turq, A., 2013. The Late Middle Palaeolithic in Southwest France: new TL data for the sequence of Pech de l'Azé IV. Quaternary International, 294, 160-167.

Riel-Salvatore, J., Clark, G.A., 2001. Grave markers: Middle and early Upper Paleo-lithic burials and the use of chronotypology in contemporary Palaeolithic research. Current Anthropology 42, 449-479.

Ruebens, K., Romanowska, I., Bynoe, R. (eds.), 2012. Unravelling the Palaeolithic: 10 years of research at the Centre for the Archaeology of Human Origins (CAHO, University of Southampton). University of Southampton Series in Archaeology 8 and BAR International Series 2400.

Sim, A. K., Thomsen, K. J., Murray, A. S., Jacobsen, G., Drysdale, R.,Erskine, W., 2014. Dating recent floodplain sediments in the Hawkesbury-Nepean River system, eastern Australia using single-grain quartz OSL. Boreas, 43, 1-21.

Smirnov, Y., 1989. Intentional human burial:Middle Palaeolithic (Last Glaciation) beginnings. J World Prehist 3, 199-233.

27 Sonneville-Bordes, D. de, 1960. Le Paléolithique Supérieur en Périgord. Bordeaux: Delmas.

Sonneville-Bordes, D. de, Montureux, B., 1955. L'Abri de Caminade, Comune de Canéda (Dordogne): étude préliminaire. Bulletin de la Société préhistorique française, 52, 608-619.

Soressi, M., Jones, H.L., Rink, W.J., Maureille, B., Tillier, A.m., 2007. The Pech-de-l'Aze I Neanderthal child: ESR, uranium-series, and AMS $14 C$ dating of its MTA type B context. Journal of Human Evolution, $52,455-466$.

Spooner, N.A., 1994. The anomalous fading of infrared-stimulated luminescence from feldspar.

34 Radiation Measurements 23, 625-632. 
Straus, L., 1989. Grave reservations: more on Palaeolithic burial evidence. Current Anthropology 30, 633-634.

Talamo, S., Richards, M., 2011. A comparison of bone pretreatment methods for AMS dating of samples $>30,000$ BP, Radiocarbon 53, 443-449.

Thiel, C., Buylaert, J.P., Murray, A., Terhorst, B., Hofer, I., Tsukamoto, S., Frechen, M., 2011. Luminescence dating of the Stratzing loess profile (Austria) - testing the potential of an elevated temperature post-IR IRSL protocol. Quaternary International 234, 23-31.

Thomsen K. J., Murray A. S., Bøtter-Jensen L., 2005. Sources of variability in OSL dose measurements using single grains of quartz. Radiation Measurements, 39, 47-61.

Thomsen K.J., Murray A.S., Bøtter-Jensen L., Kinahan J., 2007. Determination of burial dose in incompletely bleached fluvial samples using single grains of quartz. Radiation Measurements 42, 370379.

Thomsen K.J., Murray A.S., Jain M., Bøtter-Jensen L., 2008. Laboratory fading rates of various luminescence signals from feldspar-rich sediment extracts. Radiation Measurements 43, 1474-1486.

Thomsen K. J., Murray A. S., Jain M., 2012. The dose dependency of the over-dispersion of quartz OSL single grain dose distributions. Radiation Measurements 47, 732-739.

Thomsen, K.J., Murray, A.S., Buylaert, J.-P., Jain, M., Helt-Hansen, J., Aubry, T., submitted to Quaternary Geochronology. Testing single-grain quartz OSL methods using known age samples from the BordesFitte rockshelter (Roches d'Abilly site, Central France).

Turq, A., Dibble, H.L., Faivre, J.-P., Goldberg, P., McPherron, S.P., Sandgathe, D., 2008a. Le Moustérien du Périgord Noir : quoi de neuf ?, In: Jaubert, J., Bordes, J.-G., Ortega, I. (Eds.), Les sociétés du Paléolithique dans un Grand Sud-Ouest de la France : nouveaux gisements, nouveaux résultats, nouvelles méthodes. Mémoire XLVII de la Société Préhistorique Française, Paris.

Turq A., Jaubert J., Maureille B., Laville D., 2008b. Le cas des sépultures néandertaliennes du Sud-Ouest : et si on les vieillissait ? In, Vandermeersch B., Cleyet-Merle J.-J., Jaubert J., Maureille B. et Turq A. (éds), Première humanité, gestes funéraires des Néandertaliens. Paris : Réunion des Musées Nationaux, 40-41.

Turq, A., Dibble, H. L., Chiotti, L., Goldberg, P., McPherron, S.P., Sandgathe, D., Bruxelles, L., Guérin, G., Hublin, J.-J., Lin, S., Madelaine, S., Maureille, B., Mercier, N., Penhouet, Y., Sinet Matiot, V., Steele, T.E., Talamo, S., 2012. La Ferrassie: Rapport d'Operation pour l'Annee 2012. Available online at the address : http://www.oldstoneage.com/publications.shtml

Vandermeersch, B., 1976. Les sépultures néandertaliennes. In Lumley de H. (éd.), La Préhistoire Française. T.1.1, civilisations paléolithiques et mésolithiques. Paris : éd. du CNRS, p. 725-727.

Vieillevigne, E., Bourguignon, L., Ortega, I., Guibert, P., 2008. Analyse Croisée des Données Chronologiques et des Industries Lithiques dans le Grand Sud-Ouest de La France (OIS 10 à 3). Paléo 20, 145-165.

Wallinga, J., Bos, A.J.J., Dorenbos, P., Murray, A.S., Schokker, J., 2007. A test case for anomalous fading correction in IRSL dating. Quaternary Geochronology 2, 216-221. 
1 Wintle AG, 1973. Anomalous fading of thermoluminescence in mineral samples. Nature 245, 143-144.

2 Wintle, A.G., Murray, A.S., 2006. A review of quartz optical stimulated luminescence characteristics and 3 their relevance in single-aliquot regeneration dating protocols. Radiation Measurements, 41, 369-391.

4 Yoshida, H., Roberts, R. G., Olley, J. M., Laslett, G. M., Galbraith, R. F., 2000. Extending the age range of 5 optical dating using single 'supergrains' of quartz. Radiation Measurements, 32, 439-446.

6 Zimmerman, D.W. 1971. Thermoluminescence dating using fine grains from pottery, Archaeometry 13, $7 \quad 29-52$.

\section{$9 \quad$ Table captions}

10 Table 1. Tentative interpretation of geological history of La Ferrassie entrance section. Archaeological

11 layers are indicated, together with the correspondence with Peyrony's stratigraphy and the lithics

12 industry. The list of sediment samples collected for luminescence dating also appears. The sectors refer 13 to the site map (Fig. 2).

14 Table 2. Dose-rate information for the luminescence samples. $\mathrm{K}, \mathrm{U}$ and $\mathrm{Th}$ contents have been

15 determined by high-resolution gamma spectrometry. Beta and gamma dose-rates have been corrected 16 for the effect of humidity in the sediments. Etching has been taken into account for the beta dose-rates.

17 See text for details.

Table 3. Equivalent doses and ages for the luminescence samples. As explained in the text, not all 'ages'

19 should be considered for the chronology: pIRIR ages in particular have here been used as bleaching

20 proxies for the sediments. For clarity, the preferred ages have been highlighted in bold and an average

21 quartz age, which should be the working value, has been calculated for each sample as the average

22 between multi-grain aliquots (including measurements performed in Bordeaux) and single grain values.

23 FER 2 is an exception to that rule: because of poor-bleaching, only the modelled single grain age

24 (calculated using the IEU, cf. section 4.3) is considered reliable and thus appears in the average column. 
1 For sample FER 12 , the $D_{e}$ values determined using the pIRIR $R_{160}$ signal systematically lie above $2 D_{0}$ (but

2 below the saturation level); these doses are reported as minimum values.

3 Table 4. Single grain OSL data. " $\mathrm{N}$ " is the number of measured grains; " $\mathrm{S}_{T}<20 \%$ " is the number of grains

4 for which the uncertainty on the first ('natural') test dose response is less than $20 \%$; "sat. (\%)" is the

5 percentage of grains that are rejected due to saturation. " $n$ " is the number of grains used in $D_{e}$

6 calculations, i.e. grains with $\mathrm{S}_{\mathrm{T}}<20 \%, \mathrm{D}_{0}>100 \mathrm{~Gy}$ and not in saturation. "CAM $\mathrm{D}_{\mathrm{e}}$ " is the weighted dose

7 calculated using the Central Age Model (Galbraith et al., 1999) and "OD" is the corresponding relative

8 overdispersion. "DR" is the dose recovery ratio, i.e. the measured to given dose ratio, calculated using

9 the CAM (see text for details). "Avg. $D_{e}$ " is the arithmetic (unweighted) average of equivalent dose

10 estimates used in the age calculation. In all columns, the values quoted in brackets are derived from

11 datasets containing grains with low $D_{0}$ values (i.e. $D_{0}<100 \mathrm{~Gy}$; see text for details). The values given for

12 FER 2* have been obtained with the IEU model (for this line, the value indicated in the "Avg. $D_{e}$ " column

13 is the dose determined with the IEU). The last column gives the CAM to unweighted average dose ratio,

14 which seems to increase when the CAM overdispersion is increased.

15 Table 5. AMS radiocarbon dating results of 4 samples from La Ferrassie. Isotopic values, C:N ratios,

16 amount of collagen extracted (\%Coll) refer to the $>30 \mathrm{kDa}$ fraction. The $\delta^{13} \mathrm{C}$ values are reported relative

17 to the VPDB standard and $\delta^{15} \mathrm{~N}$ values are reported relative to the AIR standard. Ages have been

18 calibrated using OxCal 4.2 (Bronk Ramsey and Lee, 2013) using the international calibration curve IntCal

1913 (Reimer et al., 2013). These ages can thus be directly compared with the luminescence ages.

20 Table 6. Summary of relevant ages, including radiocarbon data, presented together with available data

21 on geology, lithics, hominin remains, and fauna analysis, and in connection with marine isotope stages. 
1

2

3

4 
2 Fig. 1. Regional map, indicating the location of La Ferrassie and other important Palaeolithic sites in the

3 Dordogne region of France.

$4 \quad$ Fig. 2. Site map with newly excavated sectors and the location of luminescence samples (blue squares).

5 Fig. 3. Stratigraphic section of La Ferrassie. OSL samples are indicated as blue squares and $\mathrm{Al}_{2} \mathrm{O}_{3}: \mathrm{C}$

6 dosimeters as red circles.

7 Fig. 4. Connection between the foot of the La Ferrassie 2 individual and our stratigraphy. (a) Foot as

8 preserved, with sediments attached to it, in the Musée de l'Homme (Paris). (b) View of the sampled

9 section for micromorphology analysis, and corresponding thin sections. The best match between the

10 sediments attached to the foot and the thin sections place the LF 2 individual in Layer 5. (c) Approximate

11 find location (horizontal only) for the skeleton of LF 2, according to historic photographs of the

12 excavations carried out by Peyrony and Capitan.

13 Fig. 5. Comparison between in situ measurements (red filled squares) and infinite matrix gamma dose-

14 rates (blue open circles) as deduced from $\mathrm{K}, \mathrm{U}$ and Th contents using the conversion factors from Guérin

15 et al. (2011). All values have been corrected for moisture content following Guérin and Mercier (2012).

16 The origin of the discrepancies and their consequences on dating results are discussed in the main text.

17 See Fig. 3 for sample and dosimeter location.

18 Fig. 6. OSL ages from quartz multi-grain aliquots measured in Ris $\varnothing$ (black filled squares) and Bordeaux 19 (red filled circles).

Fig. 7. Comparison between quartz multi-grain OSL (measured in Ris $\varnothing$ : black filled squares; in Bordeaux:

21 red filled circles) and feldspar pIRIR ages. (a) pIRIR $_{290}$, open circles; (b) pIRIR ${ }_{160}$, open squares. For sample

22 FER 12, the $D_{e}$ values determined using the pIRIR 160 signal systematically lie above $2 D_{0}$ (but below the 
1 saturation level) and are thus not plotted. (c) Ratio of pIRIR to OSL ages (filled squares: pIRIR ${ }_{160}$ to OSL;

2 open squares: $p I R I R_{290}$ to $\left.O S L\right)$.

3 Fig. 8. pIRIR equivalent doses for samples FER 6, as a function of stimulation temperature (the preheat

4 temperature was in all cases $30^{\circ} \mathrm{C}$ higher than the stimulation temperature). The dashed line indicates

5 the expected equivalent dose based on measurements of quartz multi-grain aliquots, assuming a non-

6 fading pIRIR signal and no residual signal at deposition. The equivalent dose increases with stimulation

7 temperature, and the low-temperature flat region seems to indicate a bleaching plateau.

8 Fig. 9. Summary of reliable age estimates: all OSL ages obtained from quartz multi-grain aliquots

9 measured in Bordeaux (red circles) and Ris $\varnothing$ (black squares) - except for the poorly-bleached sample FER

102 - as well as from single grains (black stars) plotted as a function of Archaeological Layers. These ages

11 correspond to the bold values in Table 3 and are the ones considered in the discussion. 


\begin{tabular}{|c|c|c|c|c|c|c|c|}
\hline Layer & $\begin{array}{c}\text { Peyrony } \\
1934\end{array}$ & Industry & Description & Comments & $\begin{array}{c}\text { OSL } \\
\text { Sample }\end{array}$ & $\begin{array}{c}{ }^{14} \mathrm{C} \\
\text { Samples }\end{array}$ & Sector \\
\hline 8 & 1 & sterile & $\begin{array}{l}\text { - Light reddish rounded and } \\
\text { angular gravel that continues } \\
\text { to close to the top of the } \\
\text { profile. } \\
\text { - Connection with platform } \\
\text { above the site next to upper } \\
\text { cave remains to be } \\
\text { determined }\end{array}$ & $\begin{array}{l}\text { Derived from flat area } \\
\text { in front of upper cave }\end{array}$ & & & \\
\hline $7 b$ & $\mathrm{H}$ & Aurignacian & $\begin{array}{l}\text { - Compact, dark yellow brown } \\
\text { sandy silt with abundant } \\
\text { lithics and bone }\end{array}$ & $\begin{array}{l}\text { Dry fall talus cone } \\
\text { whose origin is a } \\
\text { platform emanating } \\
\text { from upper cave but } \\
\text { whose apex was in } \\
\text { the area near the } \\
\text { road above the } \\
\text { trench. }\end{array}$ & FER1 & & II \\
\hline $7 a$ & $\begin{array}{l}\mathrm{G} \\
\mathrm{F}\end{array}$ & Aurignacian & $\begin{array}{l}\text { - Compact, dark yellow brown } \\
\text { sandy silt with abundant } \\
\text { lithics and bone }\end{array}$ & - Idem & & & \\
\hline 6 & $\bar{E}$ & Châtelperronian & $\begin{array}{l}\text { - Compact massive reddish } \\
\text { brown silty fine sand }\end{array}$ & - Idem & FER 2 & $\begin{array}{l}\text { S-EVA } \\
26510\end{array}$ & II \\
\hline $5 b$ & $\mathrm{D}$ & $\begin{array}{l}\text { Ferrassie } \\
\text { Mousterian }\end{array}$ & $\begin{array}{l}\text { - compact bedded yellowish } \\
\text { red brown silty sand with } \\
\text { abundant } \sim \mathrm{cm} \text {-sized } \\
\text { fragments of lithics and bone } \\
\text { - Somewhat richer in lithics and } \\
\text { less sandy than } 5 \mathrm{a}\end{array}$ & - Idem & FER 3 & $\begin{array}{l}\text { S-EVA } \\
26506- \\
26507- \\
26508\end{array}$ & $\begin{array}{l}\text { II } \\
\text { II } \\
\text { III }\end{array}$ \\
\hline
\end{tabular}




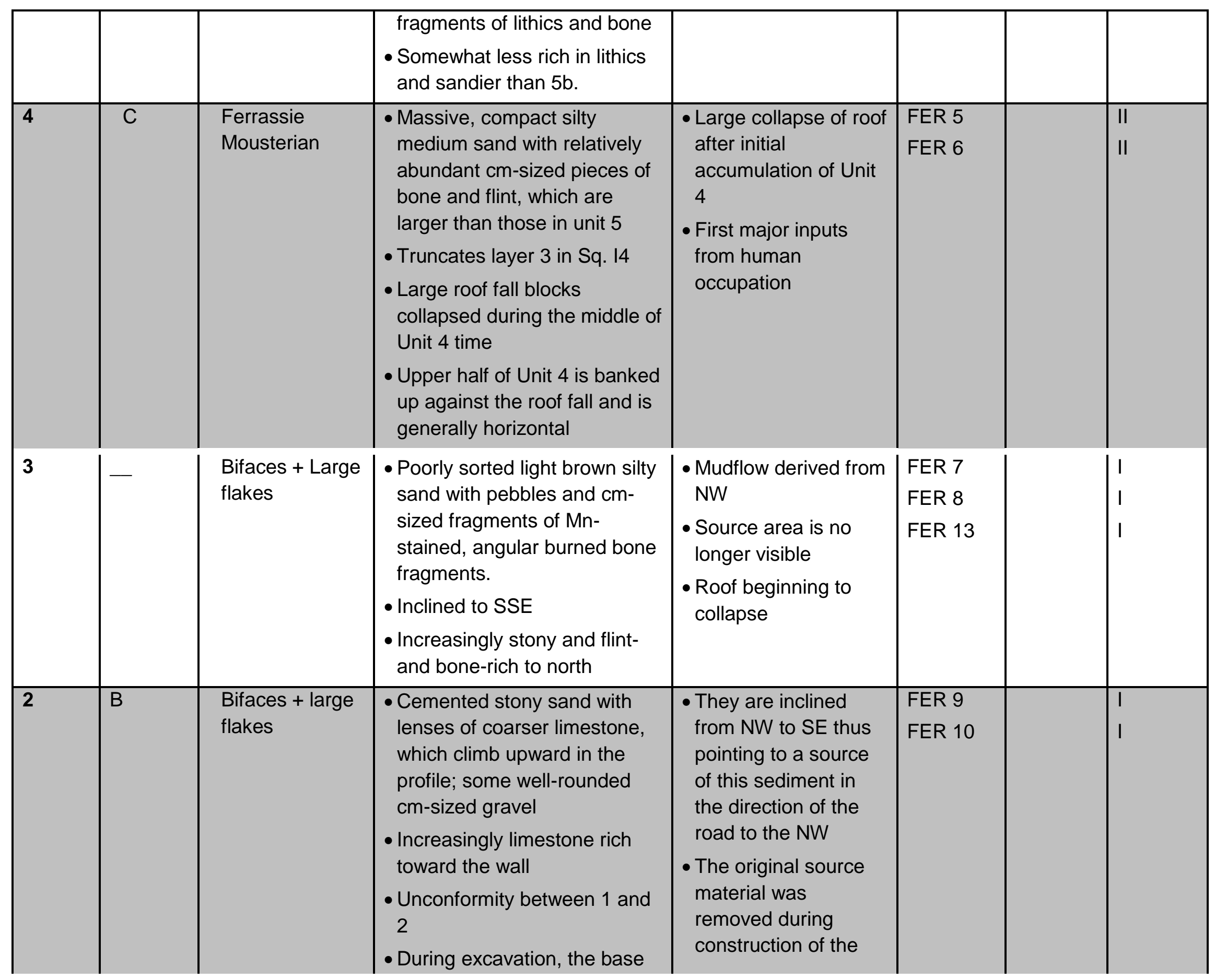




\begin{tabular}{|c|c|c|c|c|c|c|}
\hline & & & $\begin{array}{l}\text { of this unit is inclined to NW } \\
\text {-2-shots on bones also show } \\
\text { orientation in this direction } \\
\text { - Deposits are subhorizontal } \\
\text { but contact dips to the S }\end{array}$ & $\begin{array}{l}\text { road } \\
\text { - Likely solifluction } \\
\text { deposit } \\
\text { synchronously } \\
\text { affected by } \\
\text { cryoturbation that } \\
\text { also affected the top } \\
\text { of Unit } 1\end{array}$ & & \\
\hline 1 & A & $\begin{array}{l}\text { Bifaces + large } \\
\text { flakes }\end{array}$ & $\begin{array}{l}\text { - Upper part truncated by } 2 \text {. } \\
\text { - Locally red sand (with } \\
\text { éboulis) locally laminated and } \\
\text { with pockets and } \\
\text { concentrations of iron } \\
\text { pisolites }\end{array}$ & $\begin{array}{l}\text { Fluvial with } \\
\text { contributions of roof } \\
\text { fall and slabs derived } \\
\text { from the roof. }\end{array}$ & $\begin{array}{l}\text { FER } 11 \\
\text { FER } 12\end{array}$ & 11 \\
\hline
\end{tabular}


Table 2

\begin{tabular}{|c|c|c|c|c|c|c|c|c|c|c|c|c|c|c|c|c|c|c|c|}
\hline Sample & Layer & $\begin{array}{c}K \\
(\%)\end{array}$ & $\sigma$ & $\begin{array}{l}\text { U top } \\
\text { (ppm) }\end{array}$ & $\sigma$ & $\begin{array}{c}\mathrm{U} \\
\text { bottom } \\
\text { (ppm) }\end{array}$ & $\sigma$ & $\begin{array}{c}\text { Th } \\
\text { (ppm) }\end{array}$ & $\sigma$ & $\begin{array}{l}\text { Beta } \\
\text { dose } \\
\text { rate } \\
\text { (Gy/ka) }\end{array}$ & $\sigma$ & $\begin{array}{l}\text { Gamma } \\
\text { dose } \\
\text { rate } \\
\text { (Gy/ka) }\end{array}$ & $\sigma$ & $\begin{array}{l}\text { Cosmic } \\
\text { dose } \\
\text { rate } \\
\text { (Gy/ka) }\end{array}$ & $\sigma$ & $\begin{array}{l}\text { Total } \\
\text { dose } \\
\text { rate to } \\
\text { quartz } \\
\text { (Gy/ka) }\end{array}$ & $\sigma$ & $\begin{array}{c}\text { Total } \\
\text { dose rate } \\
\text { to } \\
\text { feldspars } \\
\text { (Gy/ka) }\end{array}$ & $\sigma$ \\
\hline FER 1 & 7 & 0.96 & 0.02 & 2.81 & 0.20 & 2.07 & 0.11 & 10.4 & 0.54 & 1.03 & 0.04 & 0.66 & 0.07 & 0.18 & 0.02 & 1.93 & 0.09 & 2.72 & 0.09 \\
\hline FER 2 & 6 & 0.97 & 0.02 & 2.11 & 0.18 & 1.58 & 0.08 & 10.1 & 0.52 & 0.96 & 0.04 & 0.66 & 0.07 & 0.18 & 0.02 & 1.86 & 0.09 & 2.65 & 0.09 \\
\hline FER 3 & 5 & 0.82 & 0.02 & 2.75 & 0.19 & 1.88 & 0.10 & 7.3 & 0.38 & 0.87 & 0.03 & 0.49 & 0.06 & 0.16 & 0.02 & 1.58 & 0.08 & 2.37 & 0.09 \\
\hline FER 14 & 5 & 0.75 & 0.01 & 1.86 & 0.11 & 1.96 & 0.02 & 9.8 & 0.1 & 0.84 & 0.03 & 0.20 & 0.03 & 0.17 & 0.02 & 1.27 & 0.05 & 2.07 & 0.06 \\
\hline FER 4 & 5 & 0.72 & 0.01 & 2.10 & 0.15 & 1.22 & 0.06 & 5.8 & 0.30 & 0.71 & 0.03 & 0.49 & 0.06 & 0.16 & 0.02 & 1.42 & 0.08 & 2.22 & 0.09 \\
\hline FER 5 & 4 & 1.00 & 0.02 & 2.54 & 0.20 & 1.75 & 0.09 & 8.8 & 0.46 & 0.99 & 0.04 & 0.49 & 0.06 & 0.16 & 0.02 & 1.70 & 0.09 & 2.49 & 0.09 \\
\hline FER 6 & 4 & 0.75 & 0.02 & 1.71 & 0.16 & 1.14 & 0.06 & 7.1 & 0.37 & 0.73 & 0.03 & 0.49 & 0.06 & 0.16 & 0.02 & 1.44 & 0.08 & 2.24 & 0.09 \\
\hline FER 13 & 3 & 0.83 & 0.01 & 2.13 & 0.12 & 1.88 & 0.03 & 10.4 & 0.1 & 0.91 & 0.03 & 0.29 & 0.03 & 0.17 & 0.02 & 1.43 & 0.06 & 2.22 & 0.06 \\
\hline FER 7 & 3 & 0.62 & 0.02 & 1.37 & 0.15 & 1.25 & 0.07 & 6.6 & 0.35 & 0.63 & 0.03 & 0.42 & 0.04 & 0.17 & 0.02 & 1.28 & 0.06 & 2.08 & 0.07 \\
\hline FER 8 & 3 & 0.63 & 0.01 & 1.14 & 0.12 & 1.17 & 0.06 & 6.5 & 0.34 & 0.63 & 0.02 & 0.42 & 0.04 & 0.17 & 0.02 & 1.28 & 0.06 & 2.07 & 0.07 \\
\hline FER 9 & 2 & 0.55 & 0.01 & 0.96 & 0.13 & 1.06 & 0.06 & 5.5 & 0.29 & 0.55 & 0.02 & 0.42 & 0.04 & 0.17 & 0.02 & 1.20 & 0.06 & 1.99 & 0.06 \\
\hline FER 10 & 2 & 0.52 & 0.01 & 1.41 & 0.13 & 1.27 & 0.07 & 6.0 & 0.31 & 0.57 & 0.02 & 0.42 & 0.04 & 0.17 & 0.02 & 1.22 & 0.06 & 2.01 & 0.06 \\
\hline FER 11 & 1 & 0.56 & 0.02 & 3.15 & 0.23 & 2.99 & 0.15 & 15.6 & 0.80 & 0.94 & 0.03 & 0.54 & 0.04 & 0.17 & 0.02 & 1.71 & 0.06 & 2.50 & 0.07 \\
\hline FER 12 & 1 & 0.53 & 0.01 & 1.91 & 0.16 & 2.04 & 0.11 & 12.9 & 0.66 & 0.77 & 0.03 & 0.54 & 0.04 & 0.17 & 0.02 & 1.54 & 0.06 & 2.33 & 0.07 \\
\hline
\end{tabular}




\begin{tabular}{|c|c|c|c|c|c|c|c|c|c|c|c|c|c|c|c|c|}
\hline Sample & Layer & $\begin{array}{c}\text { Nat./ given } \\
\text { dose (Gy) }\end{array}$ & $\mathrm{N}$ & $\mathrm{S}_{\mathrm{T}}<20 \%$ & $\begin{array}{l}\text { sat. } \\
(\%)\end{array}$ & $\mathrm{n}$ & $\mathrm{CAM} \mathrm{D}_{\mathrm{e}}(\mathrm{Gy})$ & $\sigma$ & $\mathrm{OD}(\%)$ & $\sigma(\%)$ & DR & $\sigma$ & Avg. $D_{e}(G y)$ & $\sigma(G y)$ & $\begin{array}{c}\text { Avg./ } \\
\text { CAM D }_{\mathrm{e}}\end{array}$ & $\sigma$ \\
\hline FER 1 & 7 & Nat. & 2400 & $101(205)$ & $4(10)$ & $97(184)$ & $70.6(67)$ & 3.0 & $29(31)$ & 3 & & & $74.0(72)$ & 3.5 & 1.05 & 0.06 \\
\hline FER 2 & 6 & Nat. & 2400 & $100(211)$ & $9(22)$ & $91(164)$ & $94.1(80)$ & 5.5 & $51(53)$ & 5 & & & $116(97)$ & 9 & 1.23 & 0.12 \\
\hline FER 2* & & Nat. & 2400 & & & & & & & & & & 78.4 & 3.5 & & \\
\hline \multirow[t]{3}{*}{ FER 3} & $5 B$ & Nat. & 2400 & 97 (190) & $1(8)$ & $96(174)$ & $60.2(56)$ & 2.7 & $35(37)$ & 3 & & & $64.6(60)$ & 3.5 & 1.07 & 0.07 \\
\hline & & 56.8 & 1200 & 64 (107) & $0(1)$ & 64 (106) & $64.9(60)$ & 2.3 & $15(17)$ & 3 & 1.14 & 0.05 & $70.8(64)$ & 3.4 & 1.09 & 0.06 \\
\hline & & 94.7 & 1200 & $50(91)$ & $0(8)$ & $50(84)$ & $94.9(91)$ & 3.2 & $12(15)$ & 3 & 1.00 & 0.05 & $99.5(91)$ & 3.5 & 1.05 & 0.04 \\
\hline FER 4 & $5 \mathrm{~A}$ & Nat. & 2400 & $70(175)$ & $0(9)$ & 70 (159) & $68.3(61)$ & 3.6 & $37(37)$ & 4 & & & $73.2(65)$ & 4.4 & 1.07 & 0.08 \\
\hline FER 7 & 3 & Nat. & 2400 & 107 (199) & $4(8)$ & $103(184)$ & $71.1(66)$ & 3.2 & $35(35)$ & 3 & & & $78.0(72)$ & 3.7 & 1.10 & 0.06 \\
\hline \multirow[t]{3}{*}{ FER 9} & 2 & Nat. & 2400 & $120(219)$ & $3(8)$ & $117(200)$ & $75.4(68)$ & 3.5 & $39(41)$ & 3 & & & $85.6(77)$ & 4.7 & 1.14 & 0.07 \\
\hline & & 56.8 & 1200 & 67 (122) & $0(1)$ & 67 (122) & $60.6(58)$ & 1.7 & $8(17)$ & 2 & 1.07 & 0.04 & $61.6(60)$ & 1.4 & 1.02 & 0.02 \\
\hline & & 94.7 & 1200 & $53(93)$ & 2 (9) & $52(85)$ & 93.4 (91) & 3.2 & $13(14)$ & 3 & 0.99 & 0.04 & $96.3(92)$ & 3.6 & 1.03 & 0.04 \\
\hline
\end{tabular}




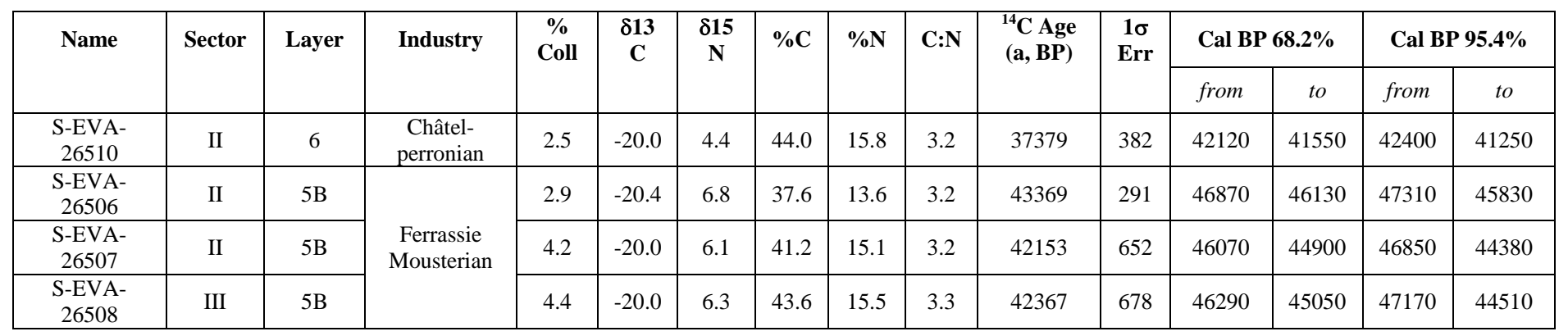




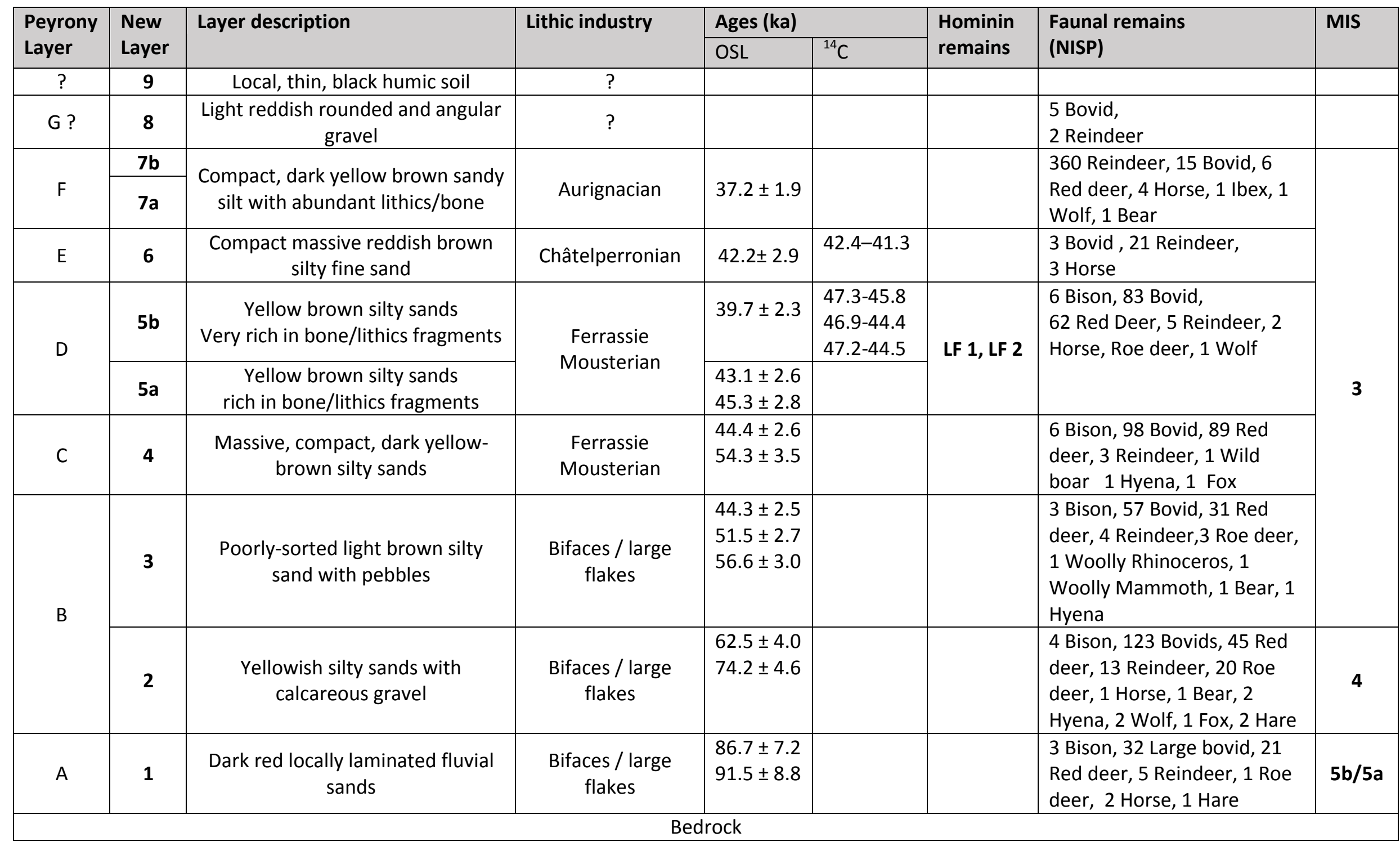


Click here to download high resolution image

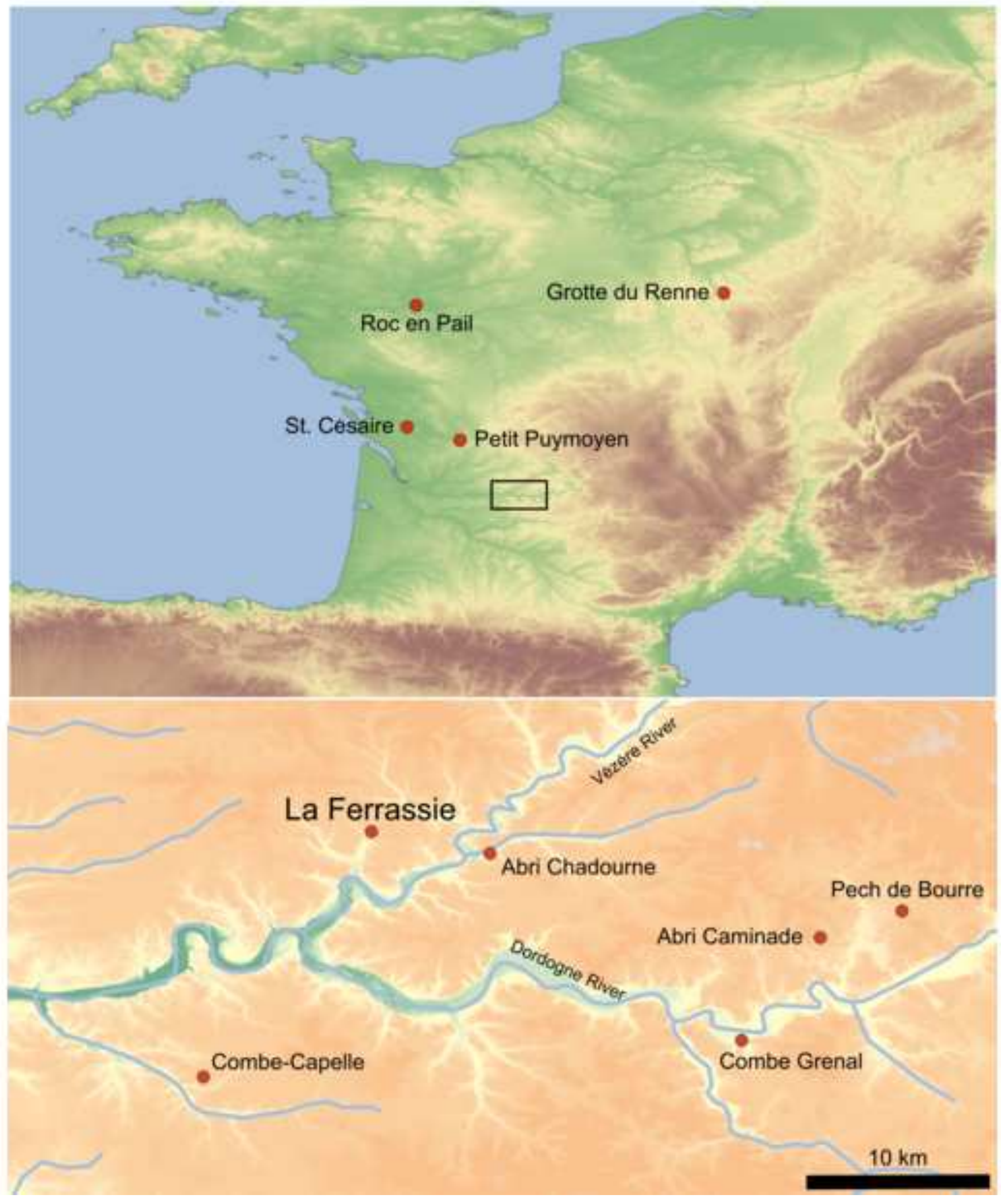




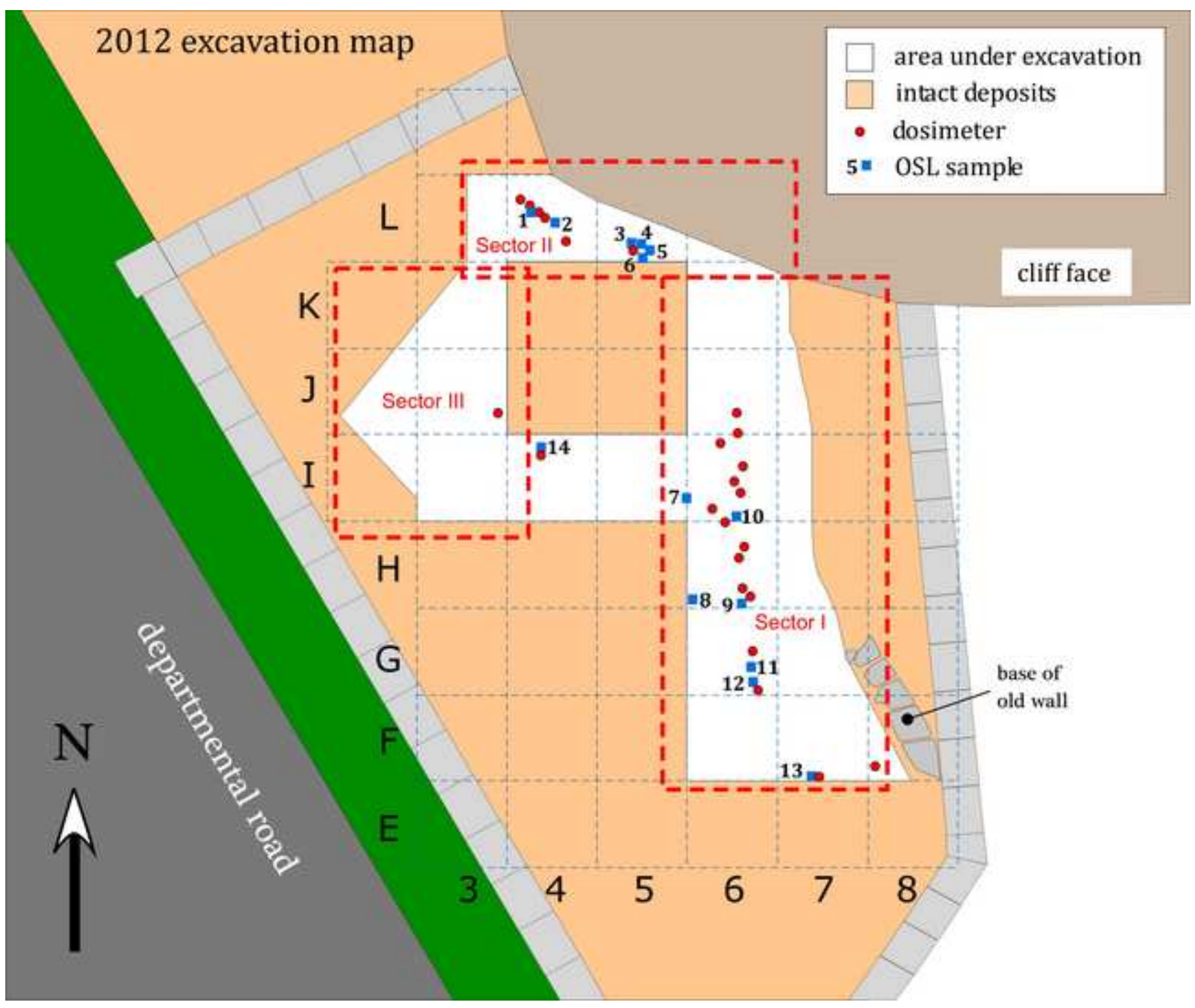




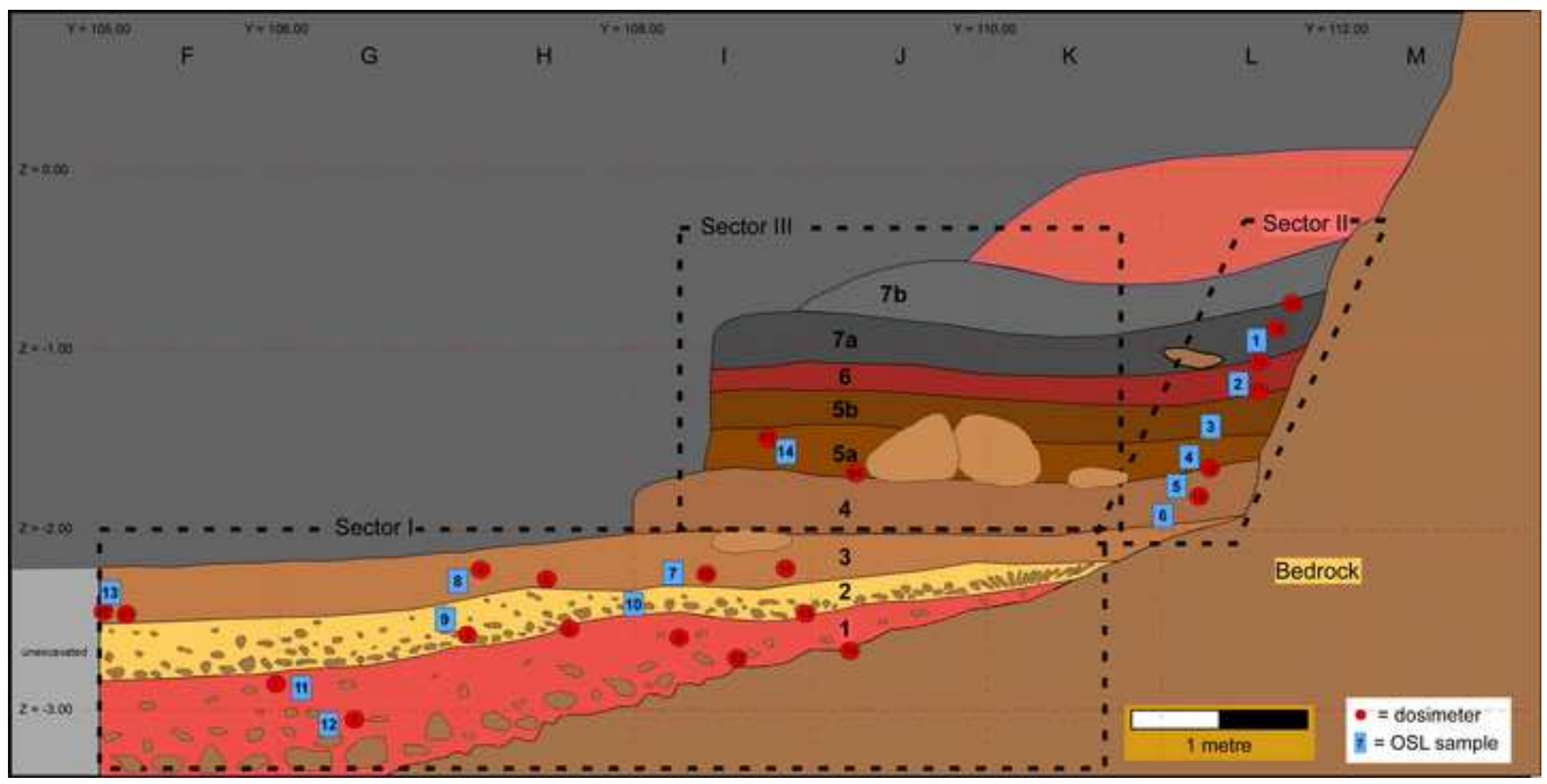


Click here to download high resolution image

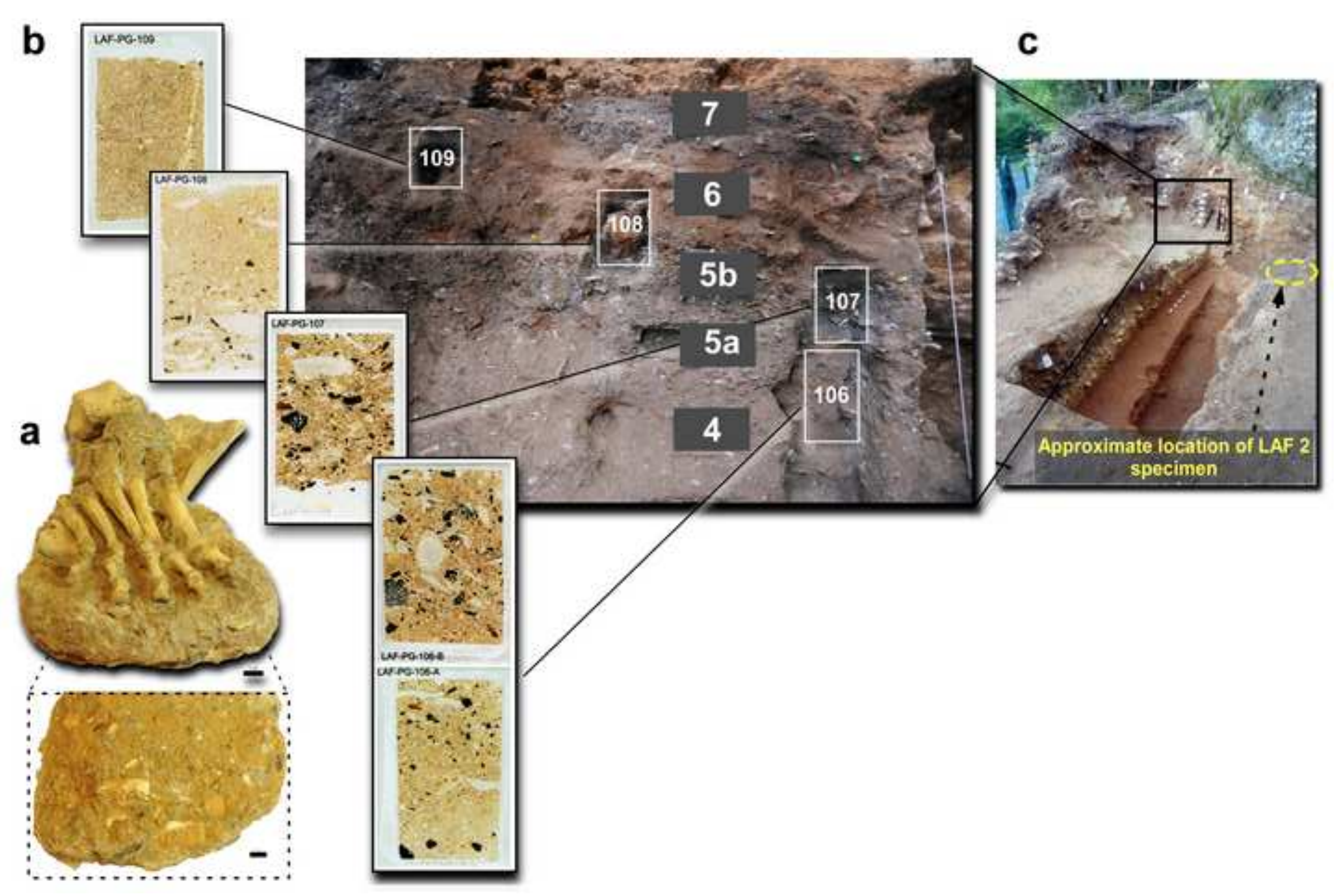




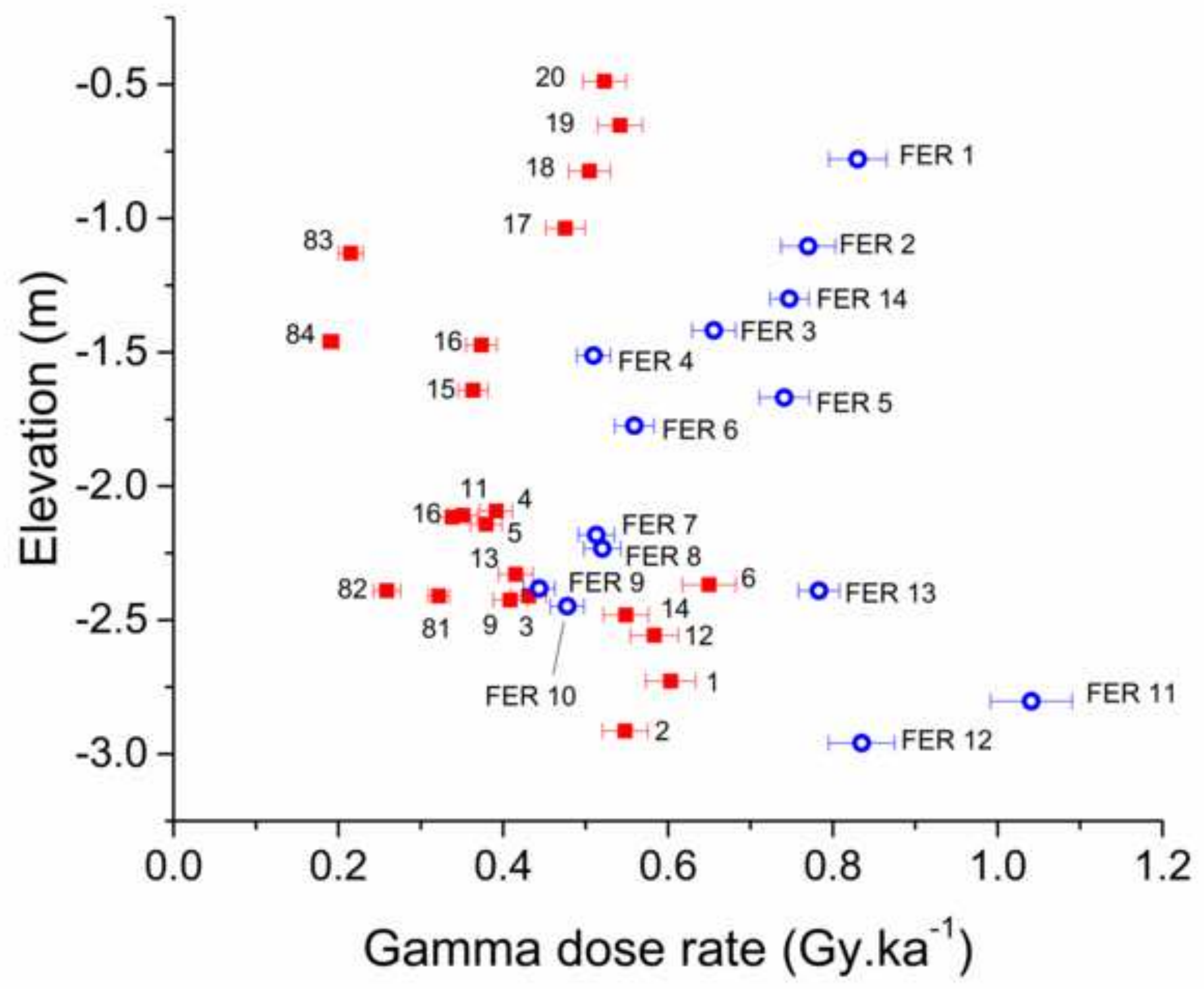


- Quartz Multi-Grain, Risø

- Quartz Multi-Grain, Bordeaux

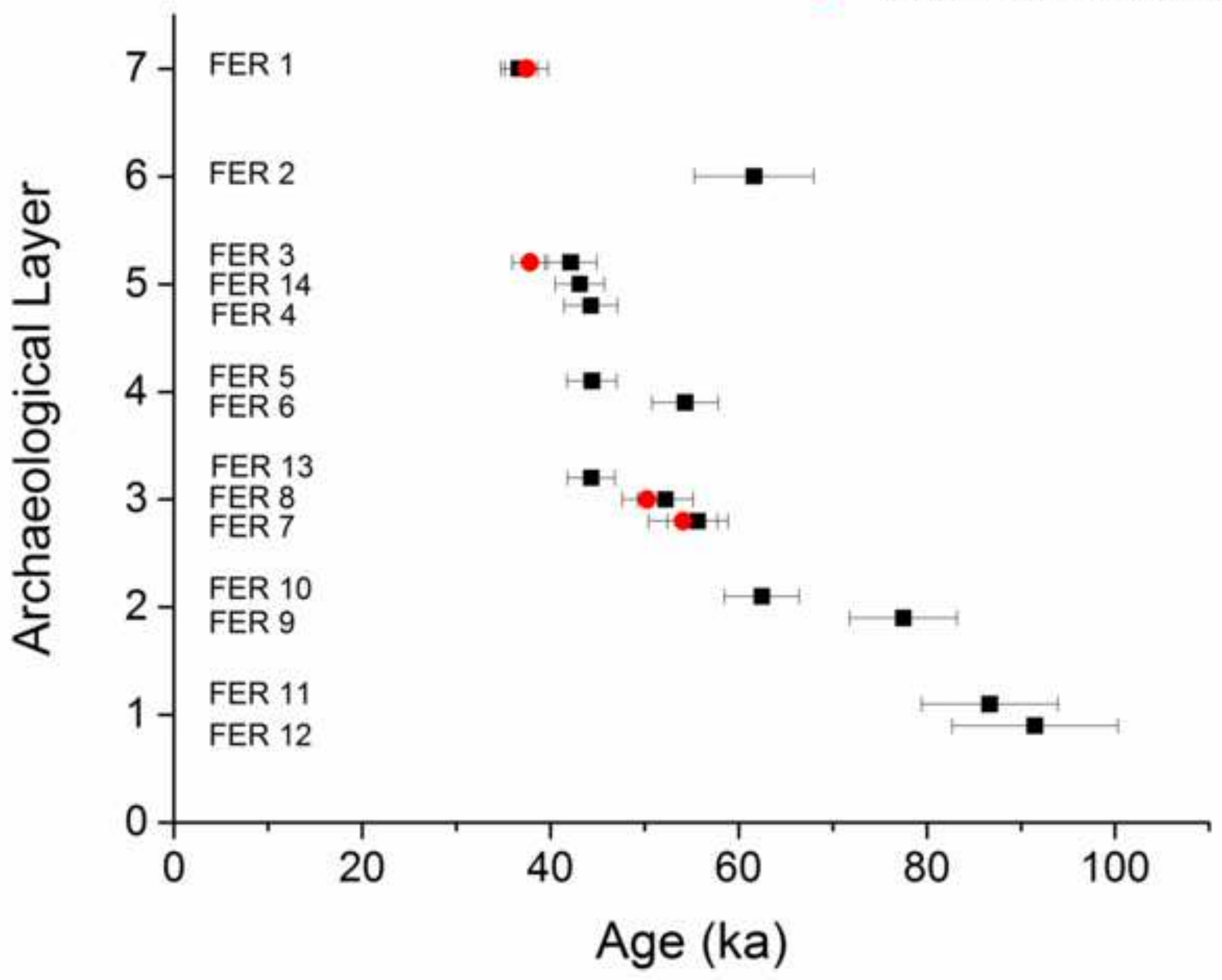




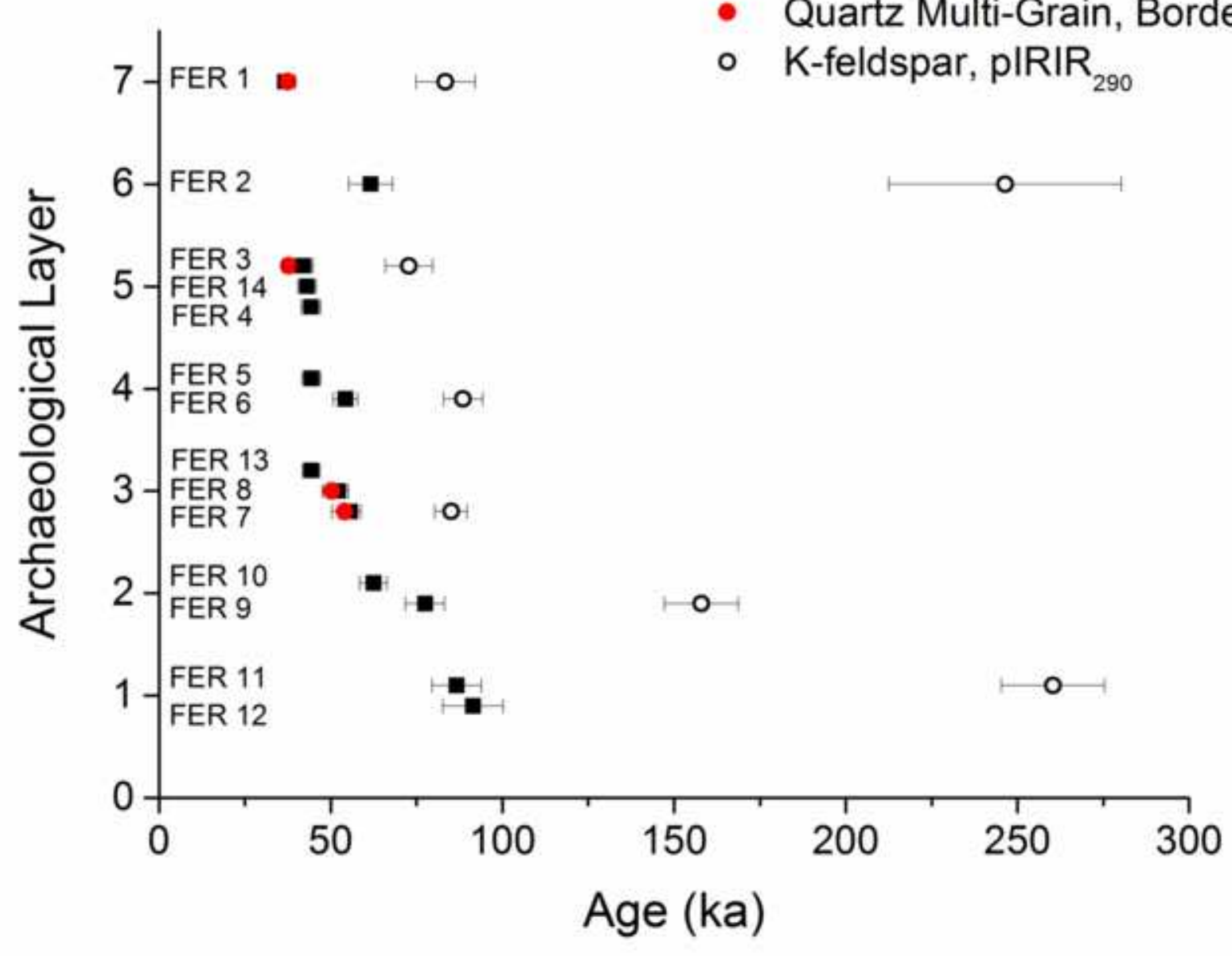

- Quartz Multi-Grain, Risø

- Quartz Multi-Grain, Bordeaux

- K-feldspar, pIRIR 290 


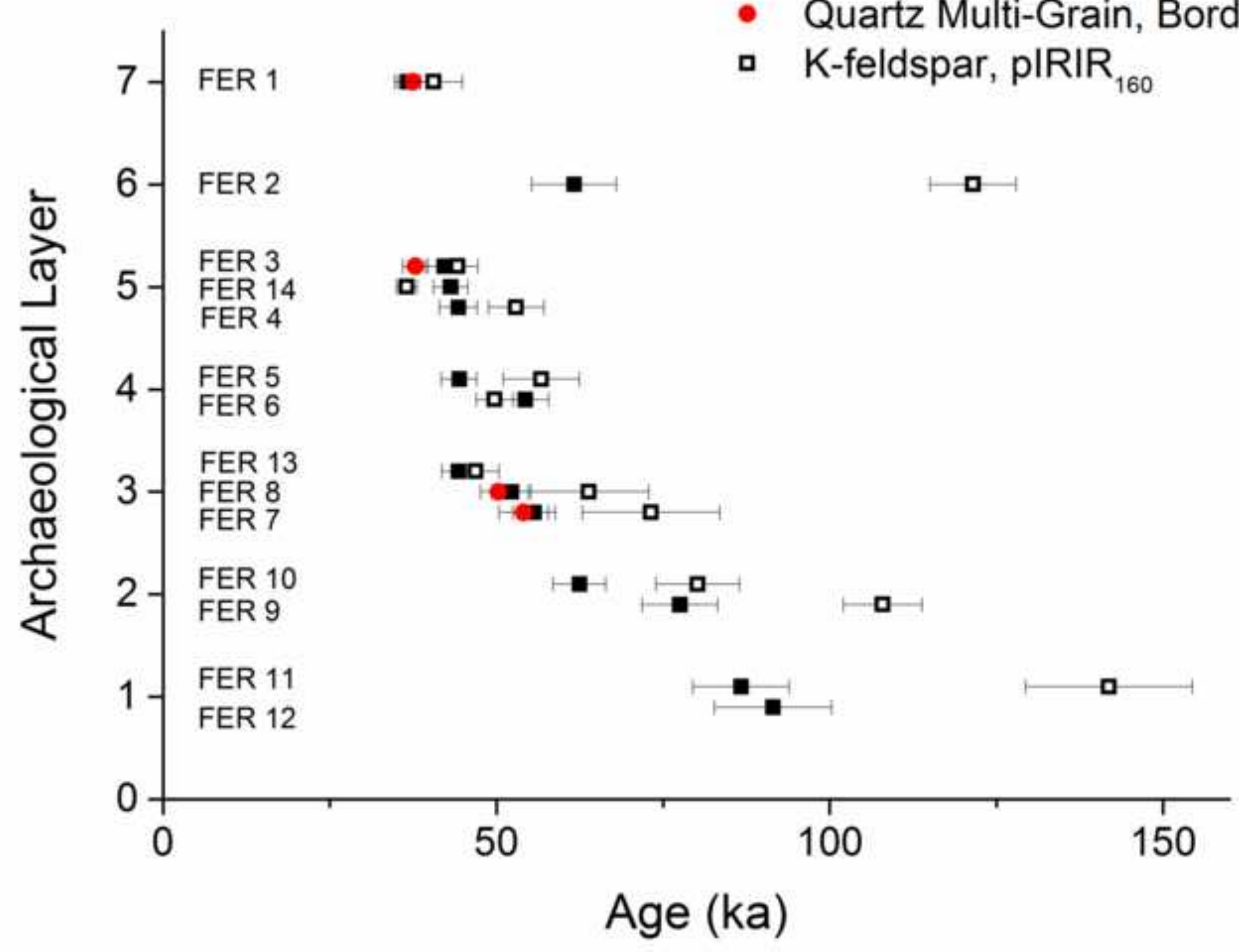

- Quartz Multi-Grain, Ris $\varnothing$

- Quartz Multi-Grain, Bordeaux

- K-feldspar, pIRIR ${ }_{160}$ 


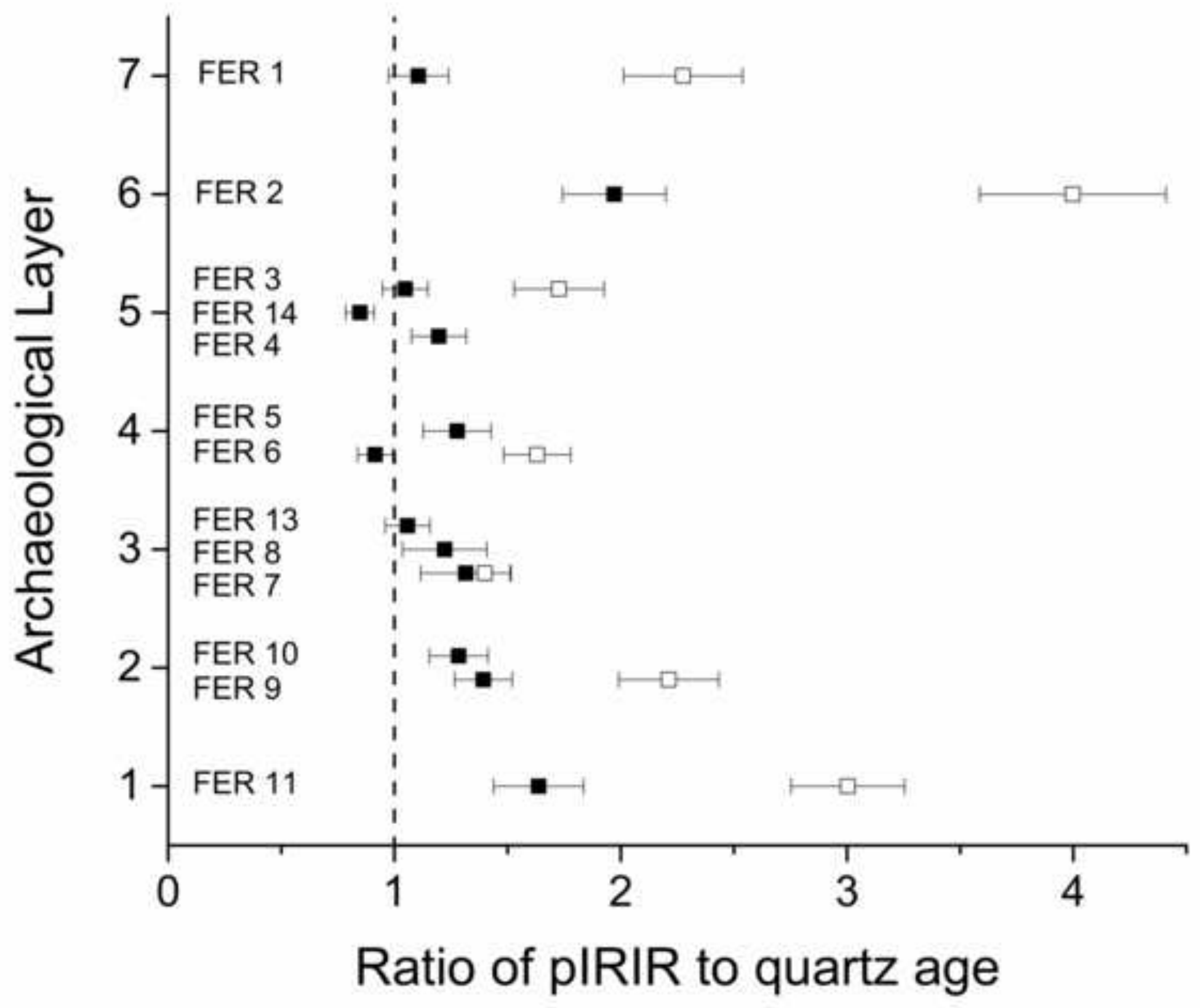




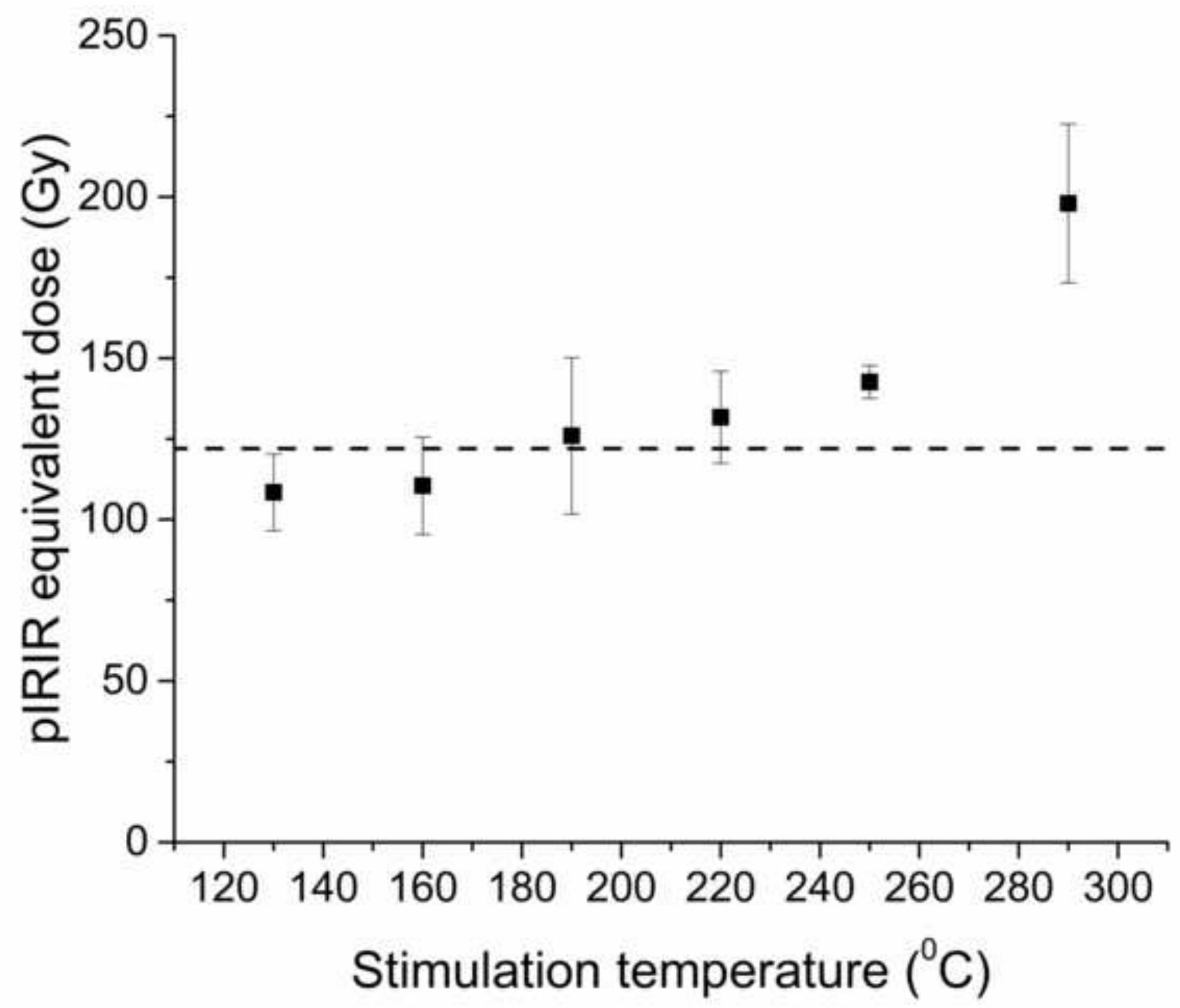




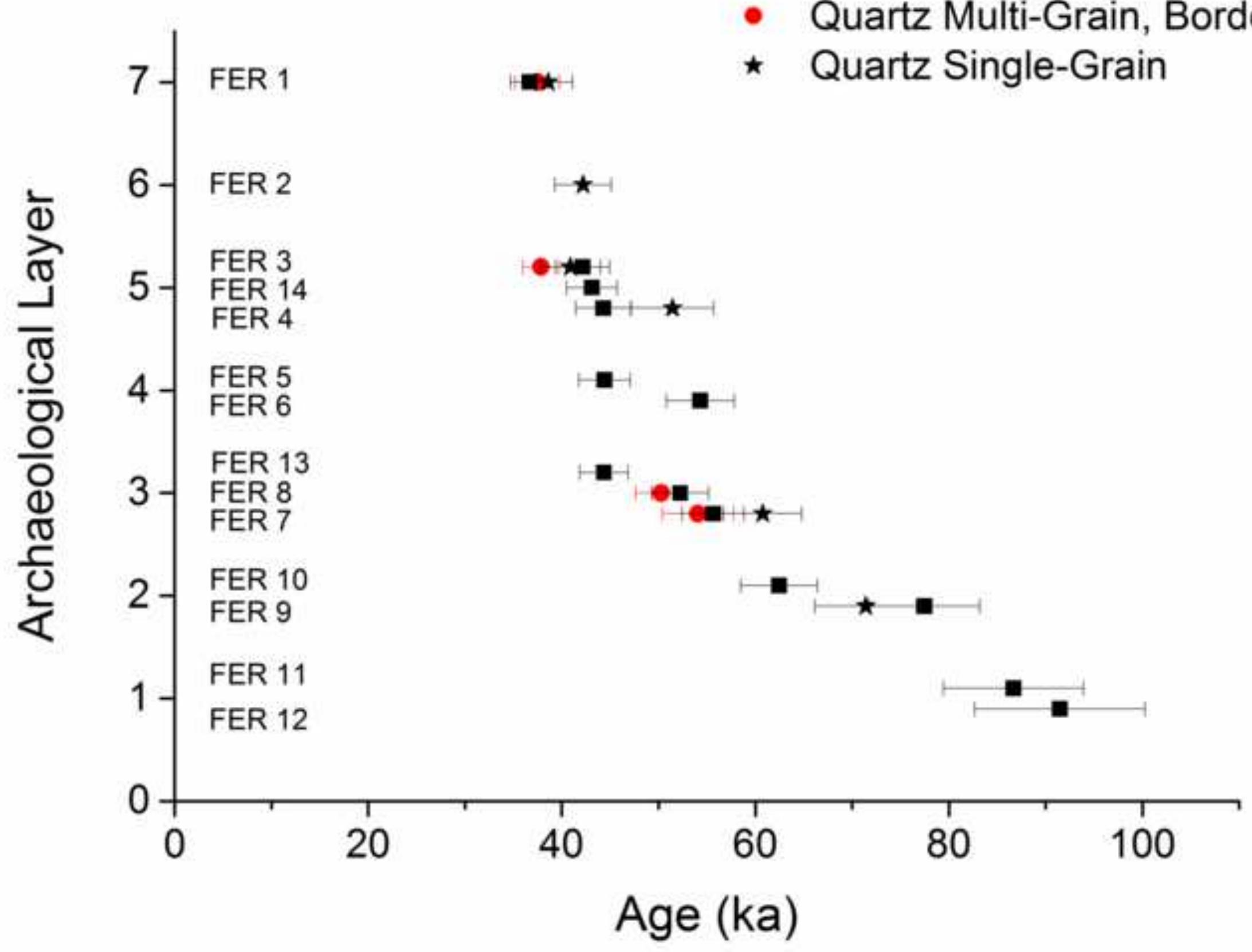

- Quartz Multi-Grain, Risø

- Quartz Multi-Grain, Bordeaux

* Quartz Single-Grain

Age (ka) 
Supplementary Material
Click here to download Supplementary Material: SupportingInformation.pdf

Supplementary Material
Click here to download Supplementary Material: Supportinglnformation.pdf click here to down

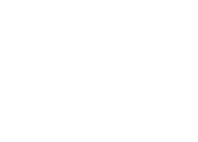
Cor Cok (1) (n)

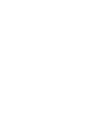
(1)

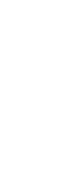
. .

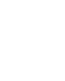
. .

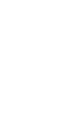

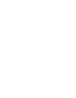
.

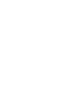

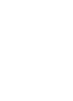

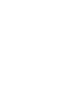

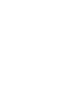

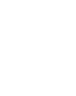

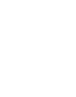
(1)

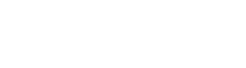
. (1) (1) (1) (1) (1) (1) (1) (1) (1) (1) (1) (1) (1) (1) (1) 列 (n) (1)

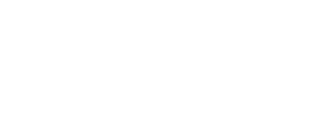


Fig. S3
Click here to download Supplementary Material: S3_La Ferrassie 3D view.pdf 